\title{
Investigation of OSN properties of PDMS membrane for the retention of dilute solutes with potential industrial applications
}

\author{
MORSHED Mahbub ${ }^{a}$, SIMONAIRE Hervé ${ }^{a}$, \\ ALEM-MARCHAND Halimab ${ }^{b}$ ROIZARD Denis ${ }^{* a}$ \\ *a Laboratoire Réactions et Génie des Procédés (UMR7274 CNRS- Université de Lorraine) \\ ENSIC - 1 rue Grandville - BP 20451 - 54001 NANCY CEDEX (FRANCE) \\ b Institut Jean Lamour, UMR 7198 CNRS-Université de Lorraine, 2 allée André Guinier - Campus \\ Artem, 54011 NANCY CEDEX (FRANCE)
}

\begin{abstract}
Few commercially available membranes can be used for Organic Solvent Nanofiltration (OSN). Applying OSN in chemical industries is nevertheless of high interest to cut with energy consumption linked to solvent recycling and soluble catalysts recovery. A commercial membrane, PERVAP4060, was used to investigate the retention of dilute solutes in toluene feeds and to mimic metathesis medium. The studied solutes were R-BINAP a neutral polyaromatic molecule used in metathesis chemistry, tetraoctylammonium bromide ( $\mathrm{To} A \mathrm{Br}$ ), a charged molecule used as a homogeneous catalyst and n-hexadecane.

Retention of polar $\operatorname{ToABr}(95 \%)$ was higher than that of neutral R-BINAP (80\%). The transfer mechanism, either pore flow or solution-diffusion, was discussed. All the results obtained suggested that the transport is governed by the solution-diffusion mechanism. The measured retentions could be explained in terms of solubility affinities and diffusion coefficients. The stability and performances of PERVAP4060 were well established, showing the strong potential for industrial applications.
\end{abstract}

Corresponding author. ROIZARD Denis, Tel.: +33 383 175217; fax: +33 383379977 .

E-mail addresses: denis.roizard@univ-lorraine.fr, denis.roizard@ensic.inpl-nancy.fr 


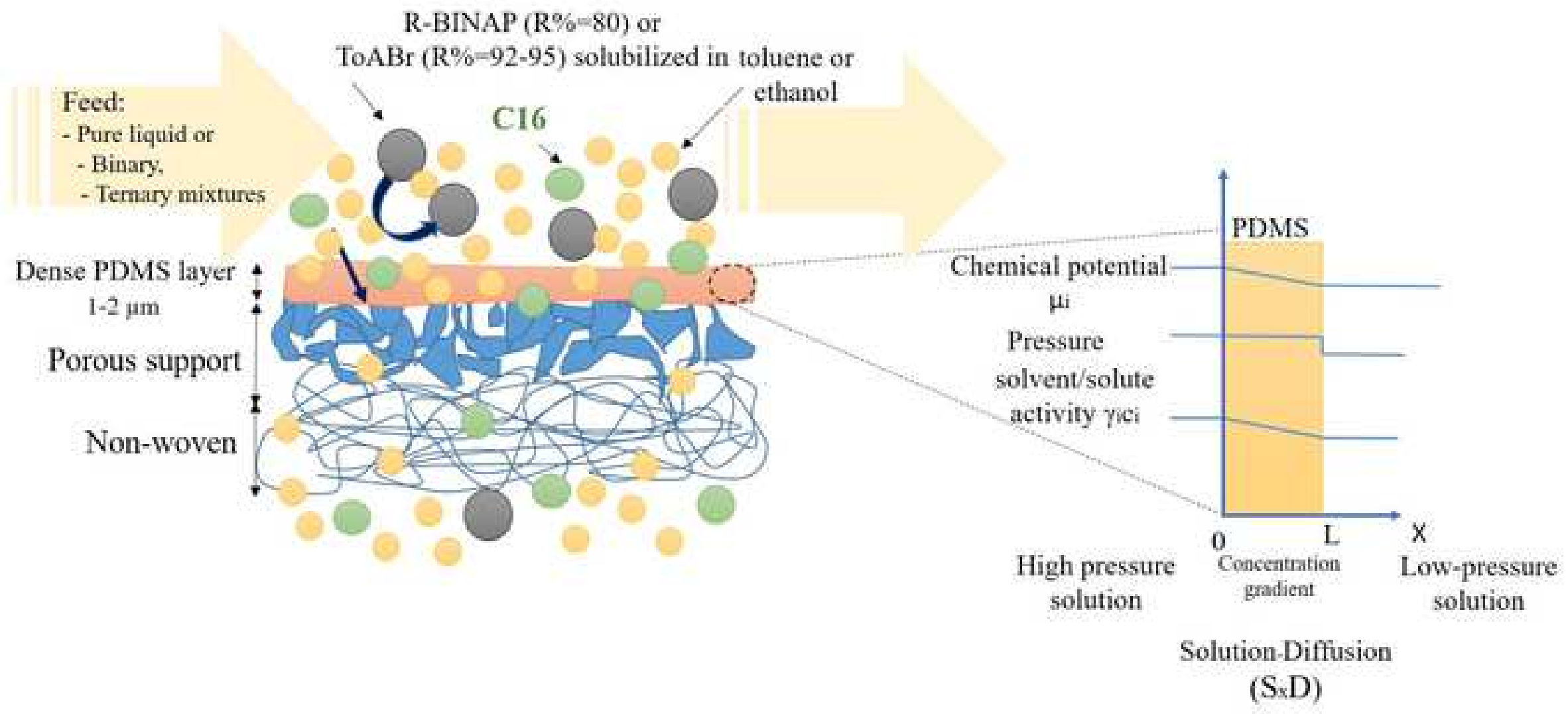


Highlights:

- Efficient OSN membranes are still lacking for industrial applications

- PDMS-based membrane exhibits high retention of dilute organic solutes in toluene

- ToABr is more rejected ( $\mathrm{R}=95 \%)$ than $\mathrm{R}$-BINAP $(\mathrm{R}=80 \%)$

- High temperature increases mass transfer without decreasing retention

- The separation of ternary model feeds confirms the membrane potential for industrial separations 


\section{INTRODUCTION}

The application of membrane technologies for the retention of dilute organic solutes, such as soluble catalysts, is an essential target from an industrial viewpoint. An early paper from Gosser [1] and several patents from the late $20^{\text {th }}$ century [2] clearly indicate the interest in and the issues with membrane separation methods, such as pervaporation (PV) or organic solvent nanofiltration (OSN) [3] [4]. This study aims to investigate the retention of diluted diphosphine ligand R-BINAP and a phase transfer catalyst ToABr from a toluene feed using commercial composite polydimethylsiloxane (PDMS) membrane PERVAP4060 in order to favor industrial catalyst separation by membrane instead of distillation.

From an industrial viewpoint, the availability of membranes that provide a high solvent flux is very important and can be a decisive point in the design of a new process, as they can dramatically reduce capital cost expenditures (CAPEX). OSN is a highly attractive and relatively new method that can be used to purify and recycle low-volatility solvents at low cost or to concentrate valuable solutes, such as homogeneous catalysts dissolved in organic media like alcohols or aromatics. Distillation can also be used for these applications, but this benchmarked technology has two significant drawbacks: the evaporation of large quantity of solvent is very energy demanding, and the temperature increase may alter the properties of the solutes. In such media, it is desirable to extract the reaction products while preserving the homogeneous catalyst, which is generally a very expensive component based on chelating ligands and specific metallic cations, such as rhodium or ruthenium.

The potential of OSN to increase the catalyst turnover number in such industrial applications [3] has been recognized for approximately two decades since its early industrial application in lube oils upgrading by EXXON [5]. However, the lack of availability of appropriate membranes for OSN with suitable molecular separation performances is a bottleneck. In this work, polymeric membranes were evaluated for the retention of 2,2'bis(diphenylphosphino)-1,1'-binaphthyl (BINAP) and tetraoctylammonium bromide (ToABr). The neutral molecule BINAP is a ligand that is key to the activity of many metal complex catalysts [6], while the charged molecule $\mathrm{ToABr}$ is mainly used as a phase transfer catalyst. These two solutes are highly soluble in toluene, which is often used as the reaction media. 
Nowadays some studies involving inorganic membranes are emerging [7]. But most of the polymeric membranes that have been used for OSN are highly crosslinked membranes based on rigid polymer backbones, such as the aromatic polyimides P84 [8], Matrimid [9], PI Starmem [10], polysulfone, polyether ether ketone, polybenzimidazoles [11], and more recently PIM [12]. Koch developed the MPF series based on a PDMS active layer in the 1990s (Koch, 2014; www.kochmembrane.com). However, the number of commercially available OSN membranes is very limited. Currently the leading suppliers are Evonik (http://duramem.evonik.com/product/duramem-puramem/en, 2018), which supplies the Starmem, Duramen, and Puramem series, and Solsep (http://www.solsep.com/OSN.htm, 2018), Koch (http://www.kochmembrane.com/Membrane-Products/Spiral/Nanofiltration .aspx, 2018), and Inopor $^{\circledR}$, which supply inorganic membranes (Inopor, 2018; http://www.inopor.com).

The retention of some solutes, including soluble catalyst using Starmem and MPF membranes, has reported mainly from EtOH feed. Unfortunately, many of these membranes are no longer available, probably due to their lack of stability over time. Thus, this work was intended to study the retention of diphosphine ligand R-BINAP from a toluene feed using a commercial composite polydimethylsiloxane membrane (PDMS), PERVAP4060.

PDMS is a well-known rubbery polymer that is widely used for liquid, VOC, and gas separations [13]. However, polydimethylsiloxane (PDMS) is often considered to be unstable in non-polar solvents, as it is a very hydrophobic polymer and can undergo severe swelling in low-polarity solvents, such as alkanes or aromatics, with swelling degrees of well over 100 $w t \%$ being observed (g of solvent/g of dry polymer) [14]. Nevertheless, this swelling property could be very interesting for OSN applications, because a high degree of polymer swelling induces high solvent permeance, which is desirable in OSN. However, a high degree of swelling is often considered to be detrimental to the high retention of solutes because the solutes could easily flow through the membrane due to the high solvent flux [15]. This issue is even more significant when highly dilute solutes are considered. Hence, the strength of the coupling effect induced by the high solvent flux when using a dense membrane may represent a significant obstacle to their use in OSN.

In order to clarify these points, two series of OSN experiments were carried out under tangential flow to investigate the performance and stability of PERVAP4060 and to determine 
the retention values of $\mathrm{TOABr}$ and BINAP in diluted toluene mixtures. $\mathrm{To} A \mathrm{Br}$ was studied in toluene as well as in an alcoholic mixture for comparison with literature data. The system was operated in steady-state mode, and the parameters studied were the feed pressure, feed flow, and feed mixture composition.

To the best of our knowledge, this multilayer membrane has never been used under OSN conditions for the retention of these catalysts at low concentration in toluene. R-BINAP is a ligand that is used to form soluble ruthenium complexes for olefin metathesis synthesis, and toluene is a typical solvent for this reaction [16] [17]. Before the investigation of the diphosphine ligand R-BINAP retention, we characterized the retention of $\mathrm{ToABr}$ from a toluene feed using PERVAP 4060 for comparison with previous results from the literature. By comparing the retention of R-BINAP, a neutral molecule, and $\mathrm{ToABr}$, a charged molecule, under similar OSN conditions, we hoped to obtain further insight into the mechanism of mass transfer through PERVAP4060 and the influence of the solvent.

\section{EXPERIMENTAL}

\section{Materials}

(R)-BINAP (white powder; purity $>94 \%$ ), $\mathrm{ToABr}$ (white powder; purity $98 \%$ ) and n-hexadecane (density $770 \mathrm{~kg} \mathrm{~m}^{-3}$; purity $>99 \%$ ) were purchased from Sigma Aldrich and used as received. The solvents toluene (purity 99.8\%) and ethanol (purity 96\%) were also obtained from Sigma Aldrich.

The membrane used for the nanofiltration experiments was PERVAP 4060, which was provided by DeltaMem AG (https://www.deltamem.ch/) in flat A4 sheet form and used as received. PERVAP 4060 is a composite membrane with an active layer of 1-2 $\mu \mathrm{m}$ of PDMS (Figure 1). 

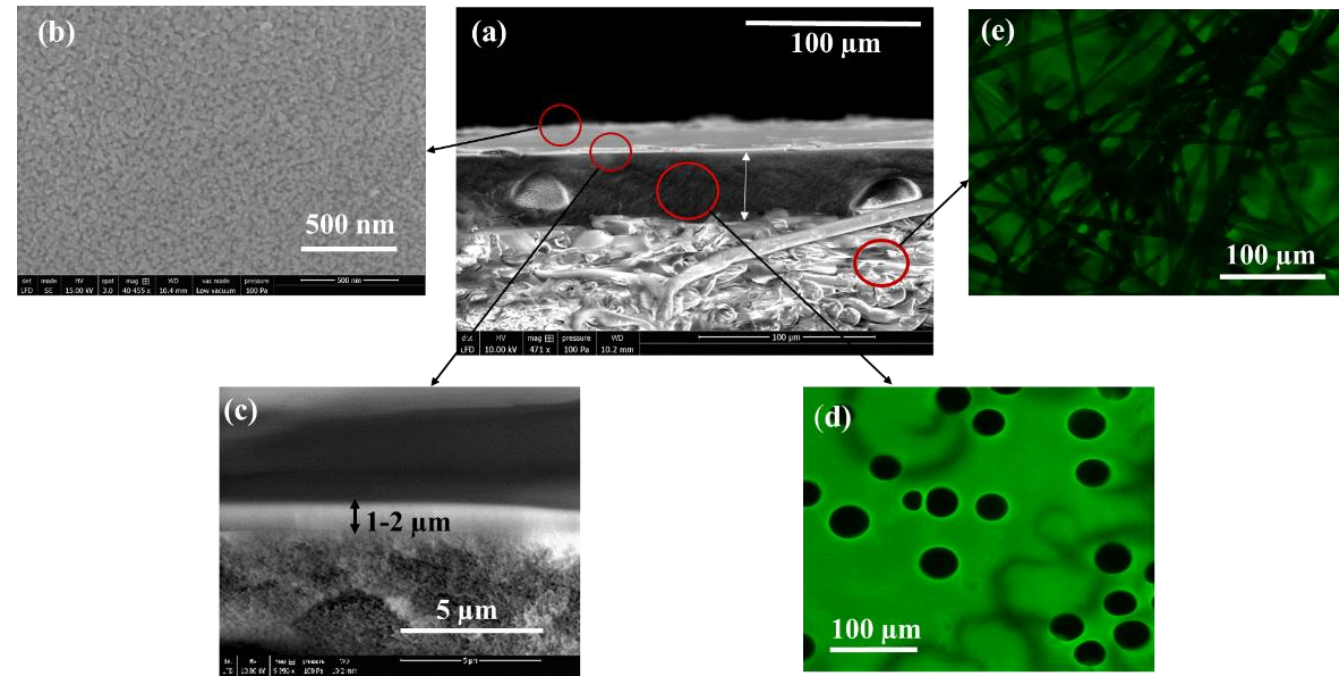

Figure 1: Characterization of the Sulzer PERVAP composite membrane by SEM and confocal microscopic images: (a) Cross-sectional view of the membrane (total thickness 200-220 $\mu \mathrm{m}$ ). (b) High-resolution image of the PDMS surface. (c) The cross-sectional view of the active layer (PDMS, thickness 1-2 $\mu \mathrm{m}$ ). (d) Top view of the PAN porous sub-layer (25-30 $\mu \mathrm{m})$. (e) PET support layer underneath the PAN sub-layer $(170-190 \mu \mathrm{m})$.

\section{Methods}

\section{OSN setup}

An OSN setup reported in a previous publication [14] was used. The setup consisted of a rectangular cross-flow cell (GE Osmonics) able to withstand pressures of up to 70 bar. The cell was used in tangential crossflow mode, in which the pressure, feed flow rate, and temperature of the feed can be controlled well. (Figure 2 a). 
(a)

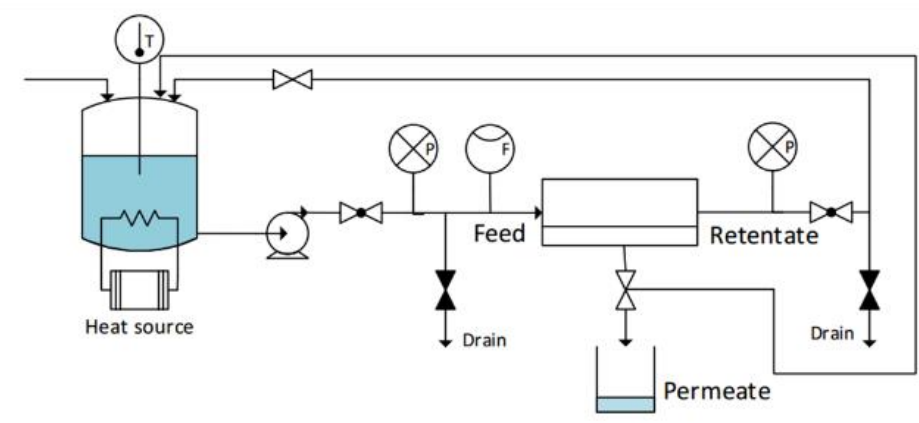

(b)

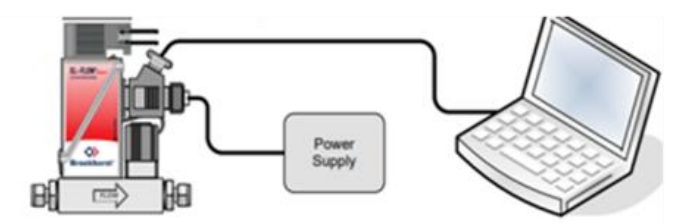

Figure 2: (a) Scheme of the OSN set-up. (b) Digital pressure control system.

In addition to the previously reported setup, the applied pressure was regulated using an IP 65 solenoid valve connected to a digital pressure transmitter system and controlled using the Flow DDE Bronchorst software. (Figure 2b). This system allowed precise pressure control over the $0-40$ bar range with a maximum fluctuation of $10 \%$ from the set value. The temperature was controlled using a Thermo Haake $\mathrm{K} 50$ with a precision of $\pm 2{ }^{\circ} \mathrm{C}$, and the cross-flow was set to $7-10 \mathrm{~kg} / \mathrm{h}$ as measured using a Cori flow (digital mass flow) meter.

\section{Membrane conditioning procedure}

Before the OSN experiments, the membrane was immersed overnight in the solvent at room temperature (pre-conditioning). The membrane coupons had dimensions of $8 \mathrm{~cm} \times 12 \mathrm{~cm}$ (including the area of the O-ring), corresponding to an effective useful membrane area of 34 $\mathrm{cm}^{2}$.

After quickly wiping the membrane surface, the coupon was mounted into the OSN cell using a double O-ring Viton seal. Next, both the upstream and downstream cells were sealed using an SPX hand pump, which ensured that the unit was free of leaks in the pressure range of 040 bar.

The conditioning began with circulating the feed through the circuit at a flow rate of $7-10 \mathrm{~kg}$ $\mathrm{h}^{-1}$ and a temperature of $30^{\circ} \mathrm{C}$. Next, a transmembrane pressure (TMP) of 10 bar was applied in steps of $2 / 3$ bar using the flow DDE software interface. At each step, the set point was compared to the actual value in the OSN, ensuring the stability of the TMP in the upstream. 
Once a pressure of 10 bar was achieved, the unit was monitored for 10-15 minutes to confirm that the pressure, cross-flow, and temperature were stable. The same procedure was repeated at 20,30, and 40 bar. After conditioning at 40 bar, the TMP was gradually decreased to atmospheric pressure following the same conditioning protocol. The aim of this pretreatment was to avoid possible hysteresis effects due to the pressure increase. The same conditioning procedure was followed for the experiments at elevated temperature.

\section{OSN procedure}

The OSN experiments were performed in a cross-flow rig, in which NF was carried out in continuous mode. The permeate was continuously recycled to ensure a steady-state concentration of the feed.

Approximately $1 \mathrm{~L}$ of $0.05 \mathrm{wt} \%$ diphosphine ligand R-BINAP and phase transfer catalyst ToABr were separately prepared offline by dissolving the solutes in toluene. Very low feed concentrations (below 0.05 wt\% R-BINAP) were prepared by dilution. High R-BINAP concentrations (higher than 0.07 wt\%) were partially achieved inline by concentrating the OSN feed. TMPs of $0-40$ bar and temperatures of $30-50{ }^{\circ} \mathrm{C}$ were studied in the OSN experiments. The conditioning procedure described above was repeated at each temperature. For the ternary mixture feed, initially, a 0.05 wt\% R-BINAP solution was used, and gradually, $1 \mathrm{wt} \%, 5 \mathrm{wt} \%$, and $10 \mathrm{wt} \% \mathrm{n}$-hexadecane (C16) were added to feed.

After conditioning, an upstream pressure was applied with a stepwise increment of $2 / 3$ bar. At each applied pressure, a 15-20 min blank run (no data point) was conducted to achieve stable permeate flow at the desired temperature and cross-flow. The permeate samples were then collected in a custom-made permeate vial with a small opening on the top to attach the vial to the OSN permeate line. This arrangement minimized evaporation loss of the solvent and ensured better measurement accuracy. At least 3-5 grams of the permeate was collected and weighed for each data point, and the corresponding collection time was recorded. At each applied pressure, at least three permeate samples were collected, with an interval of at least 20 minutes between each sample. The sample size, number of repetitions, and length of the interval between each sample ensured better measurement accuracy and system stability. 
In most cases, after the data collection at 40 bar was completed, the permeate flux and retention measurements at 10 bar were repeated. In several experiments, the used membrane was placed in a second OSN unit with a smaller surface area of $20 \mathrm{~cm}^{2}$, and the reproducibility of the data was verified using a random TMP. The maximum deviation between different OSN units was $10 \%$ for the flux. Most of the experiments were repeated more than two or three times using new membrane samples from different batches, obtained at different times.

\section{Analytical methods}

The flux (J) and rejection (R) were calculated according to the formulas given below:

$$
J=\frac{V}{A \cdot t}
$$

Where $J$ is the flux $\left(\mathrm{Lm}^{-2} \mathrm{~h}^{-1}\right), \mathrm{V}$ is the volume of the collected permeate $(\mathrm{L}), \mathrm{A}$ is the active surface area $\left(\mathrm{m}^{2}\right)$, and $\mathrm{t}$ is the time $(\mathrm{h})$.

$$
R(\%)=\left(1-\frac{C p}{C f}\right) \cdot 100
$$

where $C_{p}$ is the concentration of solute in permeate and $C_{f}$ is the concentration of the feed.

Quantitative analysis of the solutes was carried out using gas chromatography. The operational conditions of the analysis method were as follows:

- Column: HP-5 phenyl methyl siloxane. Capillary dimensions: $15 \mathrm{~m} \times 320 \mu \mathrm{m} \times 0.25 \mu \mathrm{m}$.

- Oven program:

R-BINAP: $325^{\circ} \mathrm{C}$, held for 17 min for R-BINAP using tetratetracontane as the external standard. Retention of R-BINAP at around 13-14 min and retention of the external standard at around $6 \mathrm{~min}$. The calibration and an example chromatogram are provided in the Appendices A, B. 
ToABr: $200^{\circ} \mathrm{C}$, held for $10 \mathrm{~min}$ for $\mathrm{ToABr}$ using $\mathrm{n}$-tetracosane $\left(\mathrm{C}_{24} \mathrm{H}_{50}\right)$ as the external standard. Retention of $\mathrm{ToABr}$ at around $6 \mathrm{~min}$ and retention of the external standard at around $8 \mathrm{~min}$. The calibration and an example chromatogram are provided in the Appendices.

n-Hexadecane and R-BINAP: $200^{\circ} \mathrm{C}$, held for $2 \mathrm{~min}$ for $\mathrm{n}$-hexadecane $\left(\mathrm{C}_{16} \mathrm{H}_{34}\right)$, then increased to $325{ }^{\circ} \mathrm{C}$ at a rate of $50{ }^{\circ} \mathrm{C}$ per minute and held for $17 \mathrm{~min}$ to detect RBINAP. The calibration is given in Appendices B.

- Carrier gas: He, pressure 15 psi.

- Detector: FID ( $\mathrm{H}_{2} /$ air: $\left.1 / 10\right), 380^{\circ} \mathrm{C}$.

In the dilute feed stream, the peak area of the feed and permeate were significantly lower than that of the solvent peak. Therefore, calibration and measurement were carried out using a suitable external standard, and the constant volume addition method. Each sample test was carried out in triplicate, and the results of the individual experiments were compared for the determination of solute retention.

In addition, at very dilute concentrations (as low as $0.0001 \mathrm{wt} \%$ of R-BINAP), the feed and permeate samples were first measured directly by GC, and then separate feed and permeate samples were concentrated by a factor of ten using a rotary evaporator. The new concentrations were re-measured using GC and compared with the initial results and were found to be reproducible with no more than $5 \%$ deviation. Three separate measurements were conducted using very low feed concentrations, and a new membrane sample was used each time. The retention was reproduced in each measurement. Data are given in Appendices C.

\section{RESULT AND DISCUSSION}

At the industrial scale, the use of highly dilute homogeneous catalysts for metathesis synthesis is preferable to the use of immobilized catalysts from an efficiency viewpoint. The current mature technology to recover the reaction products is distillation, but this method has the major drawback of causing the catalyst to lose its catalytic properties. OSN is considered to be a "soft" technology that can allow the separation of the product from the soluble catalyst at room temperature or moderate temperatures, thus avoiding the degradation of the expensive catalytic complex. 
An overview of the literature related to the retention of BINAP and TOABr by OSN is given in Table 1, and their schematic representations in Figure 3. As can be seen, a few OSN studies have dealt with the retention of highly dilute BINAP complexes in $\mathrm{MeOH}$ feed solutions with MPF or STARMEM membranes [18] [19] [20], but none have utilized toluene, which is one of the preferred solvents for some catalytic reactions, such as olefin metathesis.

Using MPF membranes, de Smet [18] and Vankelecom [20] reported rejection (R\%) ranging from 70 to $98 \%$ in $\mathrm{MeOH}$ and of up to $93 \%$ in $\mathrm{iPrOH}$ for the complex Ru-BINAP. A flux of $\approx 1.2$ $\mathrm{L} \mathrm{m}^{-2} \mathrm{~h}^{-1}$ was reported for MPF60, but no stable flux data were reported for the MF50 membrane, while a strong flux decline was observed with $\mathrm{MeOH}$. The transport mechanism was explained using the pore flow model, which is controversial for dense active layers [21] [14] [22]. The authors suggested that the swollen dense PDMS layer became compacted at an OSN pressure of 16 bars, which was not supported by the work of other authors [21] [14]. They cited the work of Paul as a reference, but surprisingly, in the cited paper, Paul did not support the compaction hypothesis in this low-pressure range.

The two other reports of the retention of BINAP from MeOH [10] or ionic liquid (IL)/methanol solutions [23] made use of the Starmem 112 membrane. In both cases, high initial retention values of up to $99 \%$ in pure $\mathrm{MeOH}$ were obtained. In the IL/MeOH solutions, the retention of the catalytic Ru-BINAP complex was $>92 \%$. Interestingly, both papers also reported that the retained catalyst was still active and could be recycled. The retention of the ligand BINAP itself (using the $\mathrm{P}$ atom as a marker) was higher than the retention of the Ru-catalyst, indicating the presence of metal species that were able to permeate the membrane more easily.

In the case of ToABr, more OSN studies have been reported (Table 1), using both alcohol and toluene media. In each solvent, high solvent retentions in the range of $70-100 \%$ were obtained, depending on the type of membrane used. The highest flux was recorded for PMF60, a PDMS based membrane, along with surprisingly low retention of $48 \%$ [2]. The best retention results were obtained in toluene solutions [24] [25]. Using a PDMS-PEO composite membrane, Stamatialis showed that concentration polarization occurred when the $\mathrm{ToABr}$ feed concentration was below 8 wt\%. Peeva analyzed the mass transfer through Starmem122 a polyimide membrane, using the solution-diffusion mechanism [26] and showed concentration polarization at $20 \mathrm{wt} \%(0.35 \mathrm{M})$ of $\mathrm{ToABr}$. 
Table 1: Literature overview of the retention of BINAP and ToABr catalysts by OSN.

\begin{tabular}{|c|c|c|c|c|c|}
\hline $\begin{array}{c}\text { Membrane } \\
\text { (active layer) }\end{array}$ & $\begin{array}{c}\text { Feed } \\
\mathrm{T}\left({ }^{\circ} \mathrm{C}\right) \text {, pressure (bar) }\end{array}$ & $\begin{array}{l}\text { Solutes } \\
\text { wt } \%\end{array}$ & $\begin{array}{c}\text { Flux } \\
\mathrm{Lm}^{-2} \mathrm{~h}^{-1}\end{array}$ & $\begin{array}{c}\text { Retention } \\
\%\end{array}$ & Reference \\
\hline MPF60 & $\mathrm{MeOH}, 30^{\circ} \mathrm{C}, 15$ bar & $0.3 \%$ Ru-BINAP & $\sim 2$ & 98 & [18] \\
\hline MPF50 & $\mathrm{MeOH}, 30^{\circ} \mathrm{C}, 16$ bar & $0.03 \%$ Ru-BINAP & NA & 70 & [20] \\
\hline MPF 50 & $\mathrm{THF}, 30^{\circ} \mathrm{C}, 25$ bar & 0.04\% Pd-BINAP & 166 & 95.6 & [19] \\
\hline Starmem 122 & $\mathrm{THF}, 30^{\circ} \mathrm{C}, 25$ bar & 0.04\% Pd-BINAP & 93.6 & 100 & [19] \\
\hline Starmem 240 & $\mathrm{EA}, 30^{\circ} \mathrm{C}, 25 \mathrm{bar}$ & $0.04 \%$ Pd-BINAP & 150.9 & 95.6 & [19] \\
\hline Starmem 122 & $\begin{array}{c}\mathrm{MeOH}+\text { ionic liquids }(0.01-10 \\
\text { wt\%), } 35^{\circ} \mathrm{C}, 20 \text { bar }\end{array}$ & $\begin{array}{l}0.0008 \% \text { Ru- } \\
\text { BINAP }\end{array}$ & NA & $95-99.9$ & [23] \\
\hline Starmem 122 & $\mathrm{MeOH}, 30{ }^{\circ} \mathrm{C}, 30$ bar & $0.005 \%$ Ru-BINAP & 40 & $>97.5$ & [10] \\
\hline Graph.Oxide & $\mathrm{MeOH}, \mathrm{rt}, 5$ bar & $0.001 \%$ Ru BINAP & 350 & 98 & [27] \\
\hline MPF50 & Toluene, 30 bar & $3 \% \mathrm{ToABr}$ & 19 & 48 & [2] \\
\hline Starmem122 & Toluene, 30 bar & $3 \% \mathrm{ToABr}$ & 14 & $>99$ & [28] \\
\hline MPF 50 & $\mathrm{MeOH}, 20^{\circ} \mathrm{C}, 30$ bar & $0.3 \%$ Quats & NA & $\sim 95$ & [29] \\
\hline PDMS-PEO & Toluene, $24^{\circ} \mathrm{C}, 10 \mathrm{bar}$ & $8 \% \mathrm{ToABr}$ & $\sim 16$ & 100 & [24] \\
\hline Starmem 122 & Toluene, $30^{\circ} \mathrm{C}, 30$ bar & $20 \% \mathrm{ToABr}$ & $\sim 33$ & 100 & [25] \\
\hline Starmem 122 & Toluene, $30^{\circ} \mathrm{C}, 30 \mathrm{bar}$ & $20 \% \mathrm{ToABr}$ & $\sim 35$ & 98 & [26] \\
\hline Desal 5 & Toluene $20^{\circ} \mathrm{C}, 30 \mathrm{bar}$ & $3 \% \mathrm{ToABr}$ & 4 & 62 & [30] \\
\hline Starmem122 & Toluene, $20-23^{\circ} \mathrm{C}, 30$ bar & $3-20 \% \mathrm{ToABr}$ & 70 & 93-97 & [31] \\
\hline Starmem122 & $\begin{array}{l}\text { Toluene and } \mathrm{MeOH} \text { mixtures, } \\
\qquad 22^{\circ} \mathrm{C}, 30 \mathrm{bar}\end{array}$ & $\sim 0.2 \% \mathrm{ToABr}$ & 70 & 93 & [32] \\
\hline
\end{tabular}

a) MPF: PDMS active layer; b): STARMEM: polyimide top layer<smiles>c1ccc(-c2c(P(c3ccccc3)c3ccccc3)ccc3ccccc23)cc1</smiles>

\section{R-BINAP $\left(\mathrm{Mw}=624 \mathrm{~g} \mathrm{~mol}^{-}\right.$}

$\left.{ }^{1}\right)$<smiles></smiles>

Ru-BINAP $\left(\mathrm{Mw}=794.6 \mathrm{~g} \mathrm{~mol}^{-}\right.$<smiles>CC(C)(C)CC(CC(C)(C)C)CC(CC(C)(C)C)(CC(C)(C)C)CC(C)(C)C</smiles>

Figure 3: Schematic representations of diphosphine ligand R-BINAP, Ru-BINAP and phase transfer catalyst ToABr. 
Despite the fairly good results shown in Table 1, Starmem and MPF membranes are no longer commercially available.

Table 2 provides information relevant to the feed solutions used for OSN with the commercial membrane PERVAP4060 in this study: EtOH solutions of $\mathrm{ToABr}(\approx 0.05 \mathrm{wt} \%)$ and toluene solutions of R-BINAP ( $\approx 0.05 w t \%)$. C16 has been used as a simple model of an aliphatic linear product that can be produced by metathesis.

Table 2: Some specifications of the used chemicals

\begin{tabular}{|c|c|c|c|c|c|c|}
\hline Material & $\begin{array}{l}\mathrm{MW} \\
\mathrm{g} / \mathrm{mol}\end{array}$ & $\begin{array}{l}\text { Molecular } \\
\text { diameter } \\
(\mathrm{nm})^{1}\end{array}$ & $\begin{array}{l}\text { Molar } \\
\text { volume } \\
\mathrm{cm}^{3} \mathrm{~mol}^{-1}\end{array}$ & $\begin{array}{l}\text { Diffusion } \\
\text { coefficient }^{3} \\
\left(\mathrm{~m}^{2} \mathrm{~s}^{-1}\right) \times 10^{+11}\end{array}$ & $\begin{array}{l}\text { Diffusion } \\
\text { coefficient }^{3} \\
\left(\mathrm{~m}^{2} \mathrm{~s}^{-1}\right) \times 10^{+11}\end{array}$ & $\begin{array}{l}\text { Solubility } \\
\text { parameter }^{4} \\
\mathrm{MPa}^{1 / 2}\end{array}$ \\
\hline & & & & in toluene & in PDMS & \\
\hline R-BINAP & 622.7 & NA & 511 & 9.18 & 3.74 & 21.5 \\
\hline ToABr & 546 & NA & 761 & 9.75 & 4.07 & 21.9 \\
\hline C16 & 226 & 0.845 & 294.1 & 14.9 & 7.26 & 15.9 \\
\hline Toluene & 92.1 & 0.56 & 106.8 & 24 & 13.1 & 18.2 \\
\hline EtOH & 46 & 0.52 & 58.5 & 26.4 & 1.7 & 26.5 \\
\hline
\end{tabular}

\footnotetext{
${ }^{1}$ From literature

${ }^{2}$ Molar volumes calculated using HSPiP [33] except for that of $\operatorname{ToABr}$ [26]

${ }^{3}$ Diffusion coefficient of toluene and ethanol [14], other diffusion coefficient values were calculated using a modified Gierer-Wirtz equation [34]

${ }^{4}$ Solubility parameters were obtained from HsPiP estimation [33] except for $\mathrm{ToABr}$ [39].
}

\section{a) Study of the retention of $\mathrm{ToABr}$}

The active layer of PERVAP4060 is a dense layer of crosslinked PDMS approximately 1 to 2 microns thick. Despite the thickness and density of this layer, under OSN conditions, PERVAP4060 allowed fairly high toluene permeance of about $2 \mathrm{~L} \mathrm{~m}^{-2} \mathrm{~h}^{-1} \mathrm{bar}^{-1}$ (Table 3). Note that while this was the most frequently obtained value, higher values were measured for some coupons without a reduction in retention. This can be explained by variation in the thickness of the active layer from one membrane sample to another without invoking any 
compaction phenomena. Indeed, for a given coupon, no flux hysteresis was observed when the pressure was varied from 1 to 40 bar (Figure 4). The high permeance was in good agreement with the well-known affinity of dimethyl siloxane networks with toluene; toluene is a low-polarity aromatic solvent, and the active layer is a rubbery polymer that exhibits significant swelling in toluene. The solubility parameters $\left(\delta^{i}\right)$ of PDMS and toluene are quite similar: $15.4 \mathrm{MPa}^{1 / 2}$ and $18.2 \mathrm{MPa}^{1 / 2}$, respectively.

Table 3: Solvent permeance and retention of TOABr by OSN from dilute toluene and EtOH feeds (10 bar, toluene, EtOH).

\begin{tabular}{|c|c|c|c|c|c|}
\hline Membrane & Solvent & $\begin{array}{l}\text { ToABr } \\
\text { wt\% }\end{array}$ & $\begin{array}{l}\text { Permeance } \pm 5 \% \\
\mathrm{~L} \mathrm{~m}^{-2} \mathrm{~h}^{-1} \text { bar }^{-1}\end{array}$ & $\begin{array}{l}\text { ToABr } \\
\text { Retention } \% \pm 0.5\end{array}$ & Reference \\
\hline PERVAP4060 & toluene & 1 & $2.2\left(30^{\circ} \mathrm{C}\right)$ & 93.5 & \\
\hline PERVAP4060 & toluene & 0.05 & $2.2\left(30^{\circ} \mathrm{C}\right)$ & 93 & \\
\hline PERVAP4060 & toluene & 0.1 & $2.2\left(30^{\circ} \mathrm{C}\right)$ & 92.5 & \\
\hline PERVAP4060 & toluene & 0.001 & $2.2\left(30^{\circ} \mathrm{C}\right)$ & 93 & \\
\hline PERVAP4060 & $\mathrm{EtOH}$ & 0.05 & $0.35\left(30^{\circ} \mathrm{C}\right)$ & 95 & This work \\
\hline PERVAP4060 & $\mathrm{EtOH}$ & 0.1 & $0.35\left(30^{\circ} \mathrm{C}\right)$ & 95.6 & \\
\hline PDMS-PEO & toluene & 8 & $1.6\left(24^{\circ} \mathrm{C}\right)$ & 100 & [24] \\
\hline MPF 60 & toluene & 3 & 0.2 to $1.9\left(25^{\circ} \mathrm{C}\right)$ & 48 to 86 & {$[31]$} \\
\hline MPF 60 & $\mathrm{MeOH}$ & 0.3 & $0.13\left(30^{\circ} \mathrm{C}\right)$ & 98 & [18] \\
\hline
\end{tabular}

As mentioned above, the permeance was stable at pressures up to 40 bar, indicating that increased pressure does not have any effect on the swelling of the dense layer as previously reported [14]. Moreover, as PERVAP4060 has a composite structure with three layers, i.e., polyethylene terephthalate (PET) non-woven fibers as a mechanical support, polyacrylonitrile (PAN) as an ultrafiltration support, and PDMS as the top layer (Figure $2 a, d, e$ ) the steady

\footnotetext{
i SI units are $\mathrm{J}^{1 / 2} \mathrm{~m}^{-3 / 2}$, equivalent to $\mathrm{M} \mathrm{Pa}^{1 / 2}$
} 
permeance also indicates that this structure has good mechanical resistance that prevents any significant compaction phenomena at pressures of up to 40 bar.

Conversely, the permeance of EtOH was approximately ten times lower than that of toluene. The much higher solubility parameter of $\mathrm{EtOH}, \delta=26.5 \mathrm{MPa}^{1 / 2}$, qualitatively explains this result.

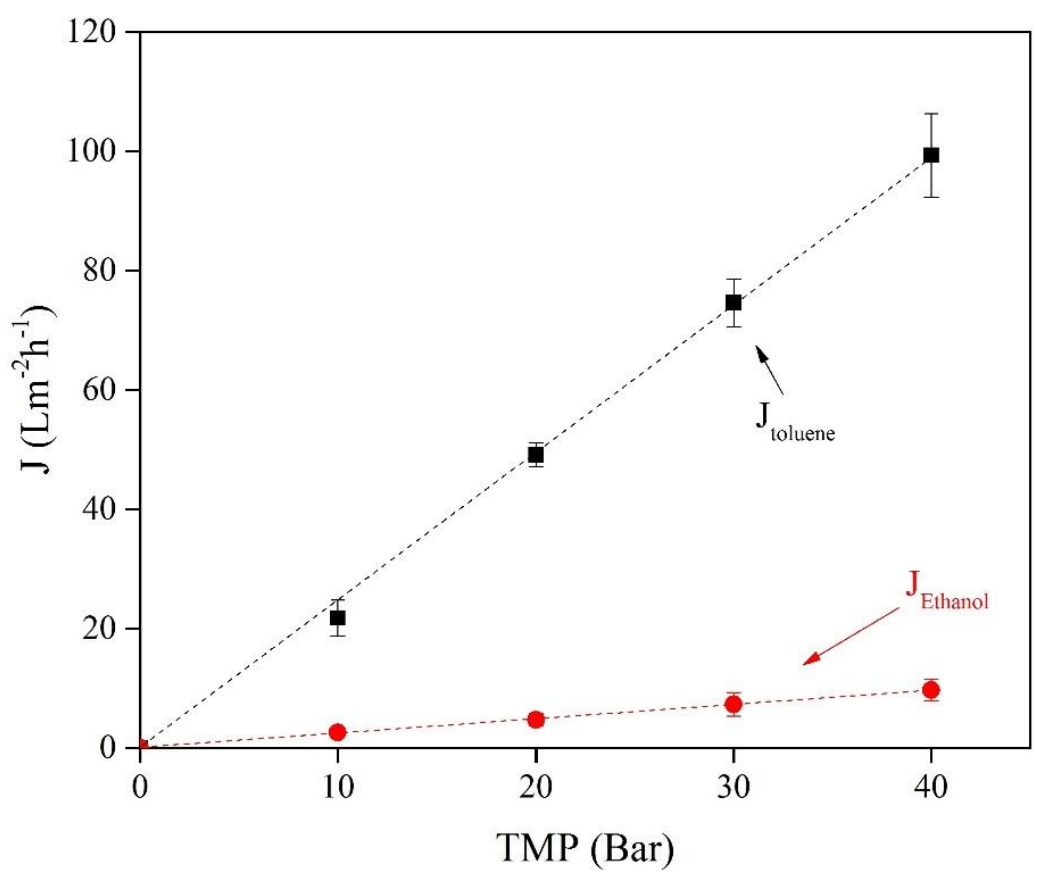

Figure 4: Pure solvent fluxes of EtOH and toluene through PERVAP6040. Deviation $\pm 5 \%$

As shown in Table 3, these results are in good agreement with those obtained by Stamatialis [24] using a composite PDMS-PEO membrane: both the flux and retention are high under analogous experimental conditions. These results demonstrate the good performance of PERVAP4060, which combines high permeance and retention above $92 \%$ in toluene and 95\% in EtOH. Previous data reported for commercial PDMS-based membranes (MPF series) showed highly variable retention and permeance values in toluene, ranging from $48 \%$ to $100 \%$ and 0.2 to $1.9 \mathrm{~L} \mathrm{~m}^{2} \mathrm{~h}^{-1}$ bar $^{-1}$, respectively. Clearly, the retention of ToABr from alcoholic feed solutions was superior for both the commercial MPF membranes and PERVAP4060 [18]_[31] but the permeance in MPF50 was at least 10 times lower. On the other hand, the STARMEM $\mathrm{PI}$-based membrane series showed promising $\mathrm{ToABr}$ retention according to the literature data 
given in Table 1; unfortunately, for technical reasons, these membranes are no longer available.

\section{b) Retention of diphosphine ligand R-BINAP}

The results obtained using BINAP as a dilute solute in toluene are presented in Figures 5-7, which show the effect of the applied pressure on the flux increase, the effect of the applied pressure over time on the OSN flux and BINAP retention, and the effect of temperature, respectively.

Figure 5 shows the OSN fluxes and retention values obtained after the conditioning procedure (feed crossflow $7-10 \mathrm{Kg} / \mathrm{h}, 15-20 \mathrm{~min}$ at each TMP in the range of $0-40 \mathrm{bar}$ ). Under these conditions, the retention of R-BINAP was almost constant and was independent of the applied pressure for pressures of up to 40 bar, reaching an average value of $80 \pm 1 \%$. The permeate fluxes increased steadily with the applied transmembrane pressure, corresponding to permeance of $\approx 2.3 \mathrm{~L} \mathrm{~m}^{-2} \mathrm{~h}^{-1}$ bar $^{-1}$, i.e., the same value as obtained previously using $\mathrm{ToABr}$ as the solute. Even though the two solutes should obviously have distinct mass transfer coefficients due to their different solubility parameters and molecular sizes (Table 2), because their molar concentrations are very low, the permeate solute flux respectively remains very low compared to the solvent flux. In the case of R-BINAP, a large neutral aromatic phosphine solute, a difference in its mobility in the PDMS network must be the main reason for the retention. These results also indicated that no significant compaction phenomena occurred with an increase in pressure. 


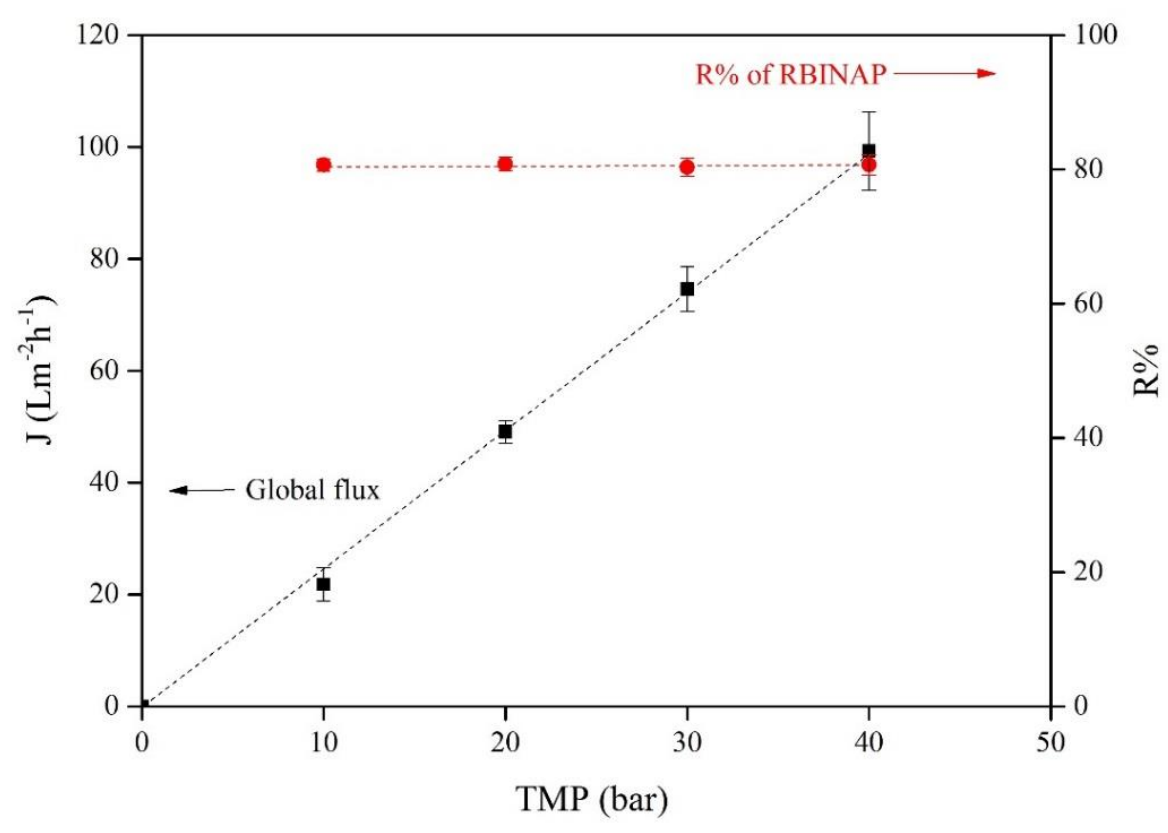

Figure 5: OSN performance of PERVAP4060 for the retention of R-BINAP from a toluene feed solution in the range 1-40 bar. R-BINAP: 0.05 mass\%. Note that the J \& R\% values at different TMP correspond to the flux and retention measured after the conditioning procedure. Continuous black line: OSN permeates flux values. Redline: retention values. Deviation $\pm 5 \%$.

Figure 6 shows the OSN fluxes and retention values obtained after several hours of continuous OSN operation at transmembrane pressures of 10 and at 20 bar. To maintain a constant feed concentration, the permeate flux was directly recirculated to the feed reservoir. Under these conditions, the retention of diphosphine ligand R-BINAP was almost constant (80\%) and independent of the applied pressure. The permeate fluxes were steady with smooth oscillations related to the temperature and pressure regulation. When the experiments were repeated after 15 or 55 hours, the same OSN fluxes were obtained, and the same selectivity was maintained. These experiments showed that the composite membrane was highly stable in the feed mixture, and still gave reproducible results after 4 days. 


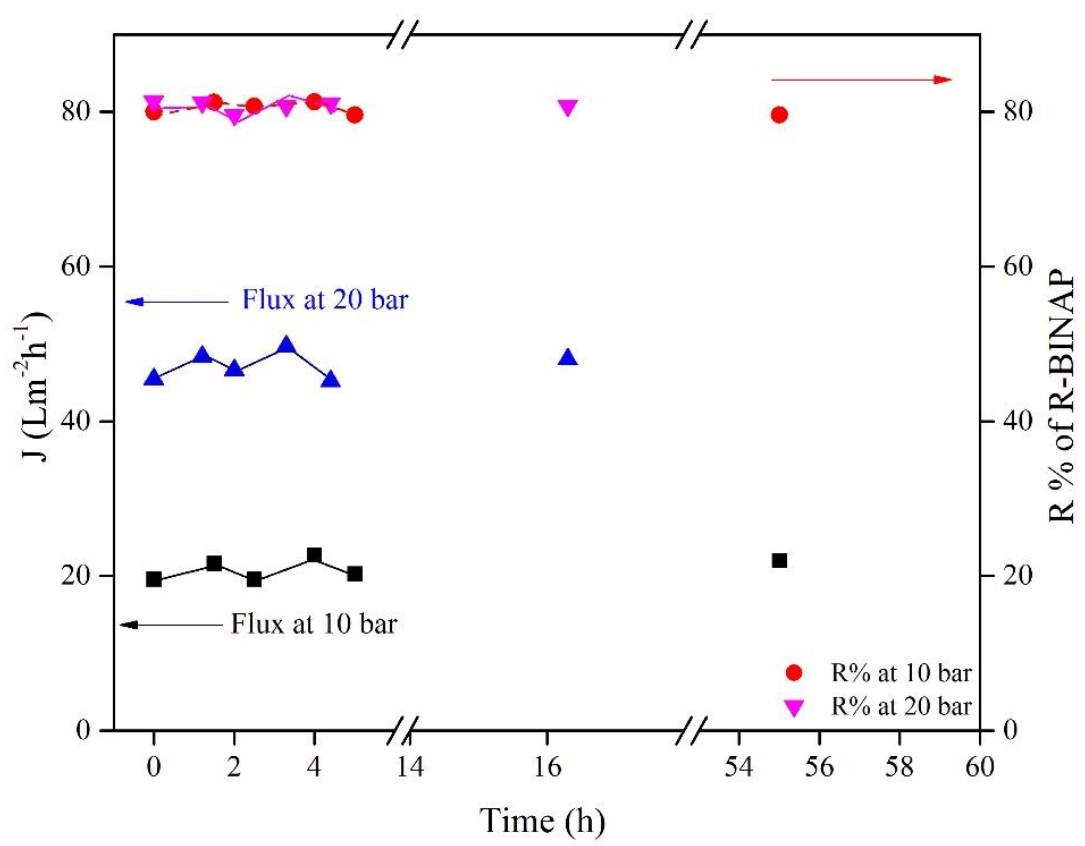

Figure 6: Effect of the applied pressure over time on the OSN flux and R-BINAP retention. Note that the J \& R\% values at zero correspond to the flux and retention measured after the conditioning procedure (feed crossflow $8 \mathrm{Kg} / \mathrm{h} \pm 20 \%, 15-20 \mathrm{~min}$ steady results at each studied transmembrane pressure in the range of 0-40 bar).

\section{c) Effect of increased temperature on the OSN flux and retention of BINAP}

The effect of temperature was first investigated in the range from 30 to $50{ }^{\circ} \mathrm{C}$ at several pressures of up to 40 bar. The objective of these experiments was to evaluate the stability of the membrane and to calculate the energy of activation. 


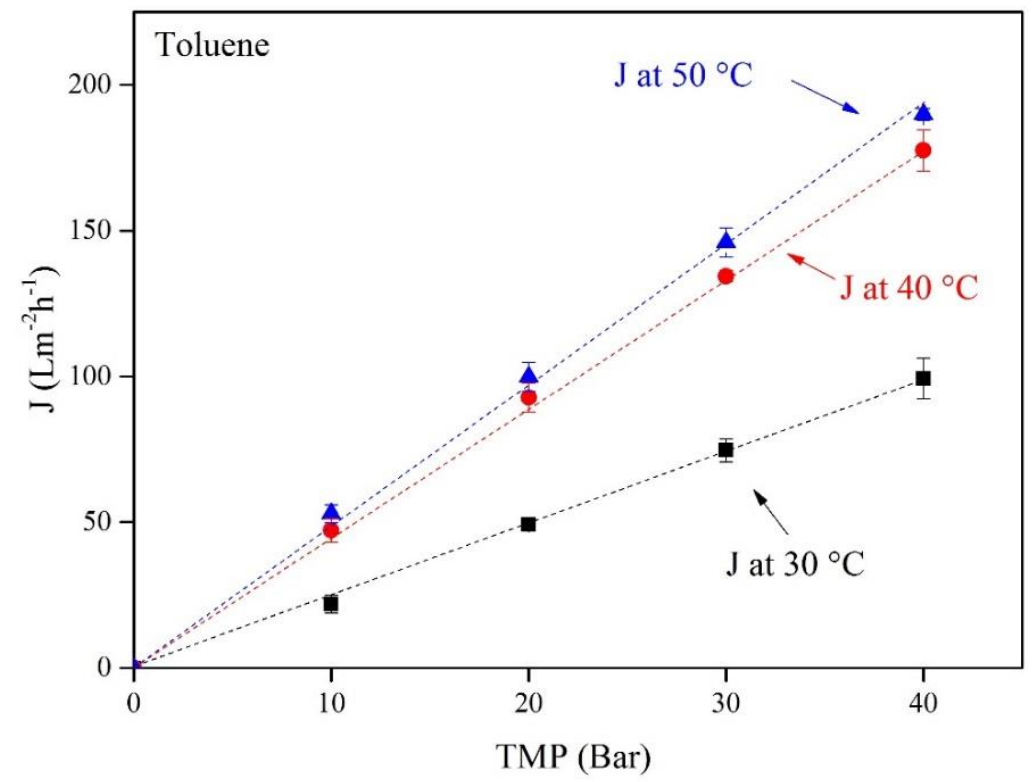

Figure 7: Effect of temperature on the pure toluene fluxes in the OSN system. Deviation \pm $5 \%$.

In Figure 7, it can be seen that for all the studied temperatures, the flux increased almost linearly with the pressure, leading to a very high flux of $180 \mathrm{~L} \mathrm{~m}^{-2} \mathrm{~h}^{-1}$ at $50{ }^{\circ} \mathrm{C}$ and 40 bar. The steady increase in the flux with an increase in pressure clearly indicates that the composite membrane was highly stable in the range from 30 to $50{ }^{\circ} \mathrm{C}$ : no apparent compaction or flux limitation related to the porous structure was observed. Taking into account the solutiondiffusion mechanism through the dense active layer, and knowing that the sorption of toluene decreases slightly with temperature, $\left(\mathrm{Ea} \approx-7.3 \mathrm{~J} \mathrm{~mol}^{-1}\right)[35]$, the strong increase in the flux is clearly related to the increase in the diffusion coefficient of toluene.

Table 4: Effect of temperature on the OSN flux and diphosphine ligand R-BINAP retention at 10 bar. Feed: 0.05\% R-BINAP - PERVAP4060

\begin{tabular}{ccc}
\hline Temperature $\left({ }^{\circ} \mathrm{C}\right)$ & $\begin{array}{c}\text { Total flux } \\
\mathrm{J}\left(\mathrm{L} \mathrm{m}^{-2} \mathrm{~h}^{-1}\right) \pm 10 \%\end{array}$ & $\begin{array}{c}\text { R-BINAP retention } \\
0.05 \text { wt } \% \pm 2 \%\end{array}$ \\
\hline 30 & 21 & 80 \\
35 & 36 & 81
\end{tabular}


The effect of temperature was then investigated using dilute feed mixtures of 0.05 wt\% RBINAP in toluene at a transmembrane pressure of 10 bar. Data were obtained for three temperatures, 30,35 , and $40^{\circ} \mathrm{C}$, and are given in Table 4 . First, the retention of R-BINAP, i.e., $\mathrm{R} \approx 80 \%$, was not altered by the increased temperature, while the flux more than doubled between 30 and $40{ }^{\circ} \mathrm{C}$. This phenomenon is striking because normally in membrane separations, a tradeoff between selectivity and permeance is observed, with a strong decrease in selectivity (or retention) occurring when the permeance is increased for any reason (temperature, pressure, or membrane thickness). Once again, these results attest to the fact that the mass transfer of toluene and that of the solute were apparently fully independent, despite the active layer being highly swollen by toluene.

In membrane separation, when the mass transfer is increased by temperature or by a pressure effect applied at the upside stream of the membrane, some coupling phenomena is often observed that induces of loss of selectivity. With R-BINAP, the increase in temperature did not induce this phenomenon. Thus it means that In the swollen PDMS active layer, the higher toluene flux due to an increase of its diffusion coefficient did not induce a significant increase of the convective force towards the solute. Hence the mass transfer of R-BINAP is not modified by the toluene mass transfer due to the increased temperature, that keeps the same ratio of solvent and solute in permeate, resulting to a constant rejection of R-BINAP from toluene.

Moreover, for porous NF membranes, the opposite situation is usually observed: with an increase in temperature, the molecular cut-off increases, leading a strong reduction in the retention values. This can be explained by an increase in the mean pore size [36].

Second, the results also indicated that the total OSN flux was unchanged compared to that of the pure solvent series, which in turn demonstrated that the high retention of R-BINAP did not influence the solvent flux and that no significant polarization concentration effect occurred during the experiment. Two factors contributed to this result: first, the concentration of R-BINAP was rather low, and the relative increase in its concentration at the membrane interface could not induce significant osmotic pressure; second, as the permeate 
was systematically recycled to the upstream reservoir, the average concentration of the solute could not increase in the feed.

The increase in the flux with temperature was not linear but instead followed a power law. This effect is well-known in gas permeation and pervaporation but has rarely been studied in OSN [37]. Figure 8 shows the effect of temperature on the increase of the OSN flux using the Arrhenius law:

$$
\ln (J)=A \frac{-E a}{R T}
$$

where $\mathrm{J}$ has units of $\mathrm{mol} \mathrm{m} \mathrm{m}^{-2} \mathrm{~h}^{-1}, \mathrm{E}_{\mathrm{a}}$ is the activation energy in $\mathrm{J} / \mathrm{mol}$, and $\mathrm{R}$ is $8.3141 \mathrm{~J} \mathrm{~mol}^{-1} \mathrm{~K}^{-}$ 1. Both the data obtained for pure toluene and the binary mixtures were used. In the feed mixture, the concentration of BINAP was below $0.05 \mathrm{wt} \%$, and as discussed in the previous paragraph, the OSN flux was the same with and without diphosphine ligand R-BINAP.

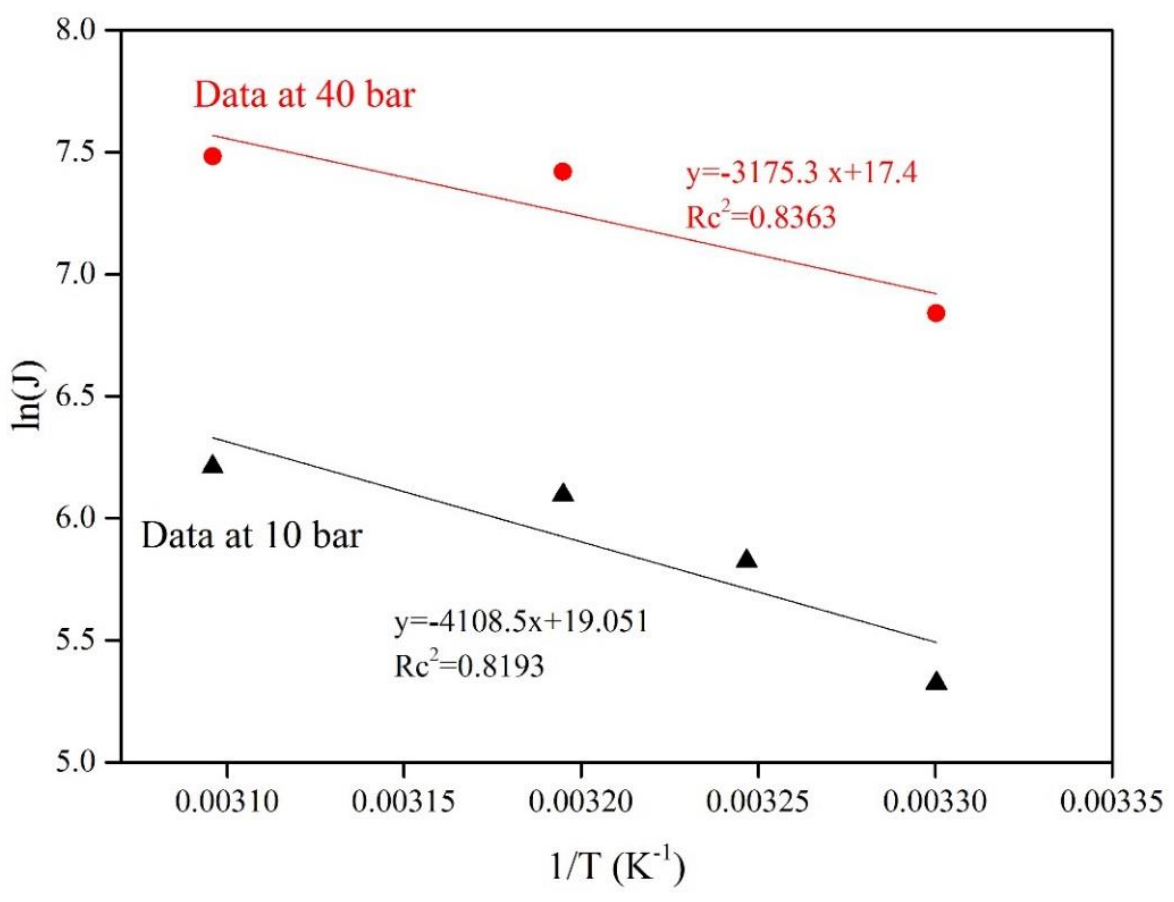


Figure 8: Arrhenius plot of the OSN flux data obtained for PERVAP4060. NB: as the R-BINAP concentration was very low $(<0.05 \mathrm{wt} \%)$, the solvent flux has been assimilated to the total OSN flux. Deviation of temperature: $\pm 2^{\circ} \mathrm{C}$.

The trends at 10 bar and 40 bar were almost the same in the $30-40 \mathrm{C}^{\circ}$ range, but a relative flux decline occurred in the $40-50{ }^{\circ} \mathrm{C}$ range. Therefore, the regression coefficients $\left(R_{c}\right)$ are below 0.9. In the range $30-40{ }^{\circ} \mathrm{C}$, the observed experimental data exhibit a better linear trend $\left(R_{c}>0.97\right)$. The calculated $E_{a}$ values at 10 and 40 bar were $34 \mathrm{~kJ} / \mathrm{mol}$ and $26 \mathrm{~kJ} / \mathrm{mol}$, respectively. As expected, the highest $E_{a}$ value was observed at 10 bar. It was well controlled that the flux decline recorded at $50{ }^{\circ} \mathrm{C}$ was not due to measurement accuracy. Moreover, no hysteresis was observed, and the previously measured values at $30^{\circ} \mathrm{C}$ were easily reproduced after the series of experiments at $50^{\circ} \mathrm{C}$. Hence, the decline in the flux at $50{ }^{\circ} \mathrm{C}$ was the result of a specific phenomenon that is not yet clearly understood (Appendices D). Two potential explanations can be suggested:

- First, at higher pressure there is an effect of compaction that affects the porous support layer and hence limits the overall mass transfer;

- Second, as the mass transfer increased a lot at 40bars, the porosity of the support becomes a physical barrier to the mass transfer and so an additive resistance.

The hypothesis of compaction at $50{ }^{\circ} \mathrm{C}$ is unlikely; if any compaction does occur, it seems to be fully reversible, that is fairly not likely. On the other hand, as mentioned above, the sorption of toluene into the PDMS layer is known to be exothermic [35]. Hence, the higher the temperature is, the higher the decrease in sorption. This effect might partially explain the observed phenomenon. Also, such phenomena may occur when the polymer network is in an unsteady state or can rearrange. For PERVAP 4060, the active layer, PDMS, is a chemically crosslink rubbery network and it is unlikely for this network to get a morphological change that would decrease the mass transfer. However, mass transfer can also be dependent on the other sublayer, which supports the active layer. Indeed, as the mass transfer increases sharply at 40 bars between 30 and $50^{\circ} \mathrm{C}$, i.e., $80 \%$ more, the support itself may become an additive resistance, limiting the overall transmembrane flux.

In conclusion, the combined effect of pressure and temperature strongly increased the OSN solvent flux, while the retention of the solute remained constant. 
Looking through OSN literature, the determination of $E_{a}$ has been reported by (Machado, 1999) for acetone with MPF membranes, giving $E_{a}=1.1 \mathrm{~kJ}$ at $30 \mathrm{bar}$.

Usually, the relationship between the flux increase and the temperature is explained in terms of a higher polymer chains mobility and a higher diffusion coefficient of the solvent when the permeation occurs through a dense selective layer. In the present case, having a highly swollen membrane due to toluene, it is interesting to compare the $E_{a}$ of toluene linked to OSN to the energy of activation $\left(E_{\mu}\right)$ only linked to the relationship between the solvent viscosity and the temperature, as calculated by Messaâdi [38]. Hence it should be underlined that $E_{\mu}$ $(9.2 \mathrm{~kJ} / \mathrm{mol})$ is much lower than $\mathrm{E}_{\mathrm{a}}(26 \mathrm{~kJ} / \mathrm{mol}$ at $40 \mathrm{bar})$ for toluene in PDMS. Once more, this result shows that the transport mechanism through the membrane is far from a viscous flow, even with a highly swollen polymer network. Machado [37] made the same observation in his work with acetone and MPF50 ( $E_{\mu}=6.8$ vs $\left.E_{a}=13.2 \mathrm{~kJ} / \mathrm{mol}\right)$ [37].

\section{d) Effect of dilution on the retention of diphosphine ligand BINAP in toluene in the range $0.0001-0.2 \mathrm{wt} \%$}

OSN experiments were carried out both at lower and higher R-BINAP concentrations than the reference concentration of $0.05 \mathrm{wt} \%$. The lower concentrations were easily prepared by dilution with an additional solvent and controlled using an external standard by GC. Calibration with an external standard was necessary at the very low concentration of 100 ppm. The results are shown in Figure 9. 


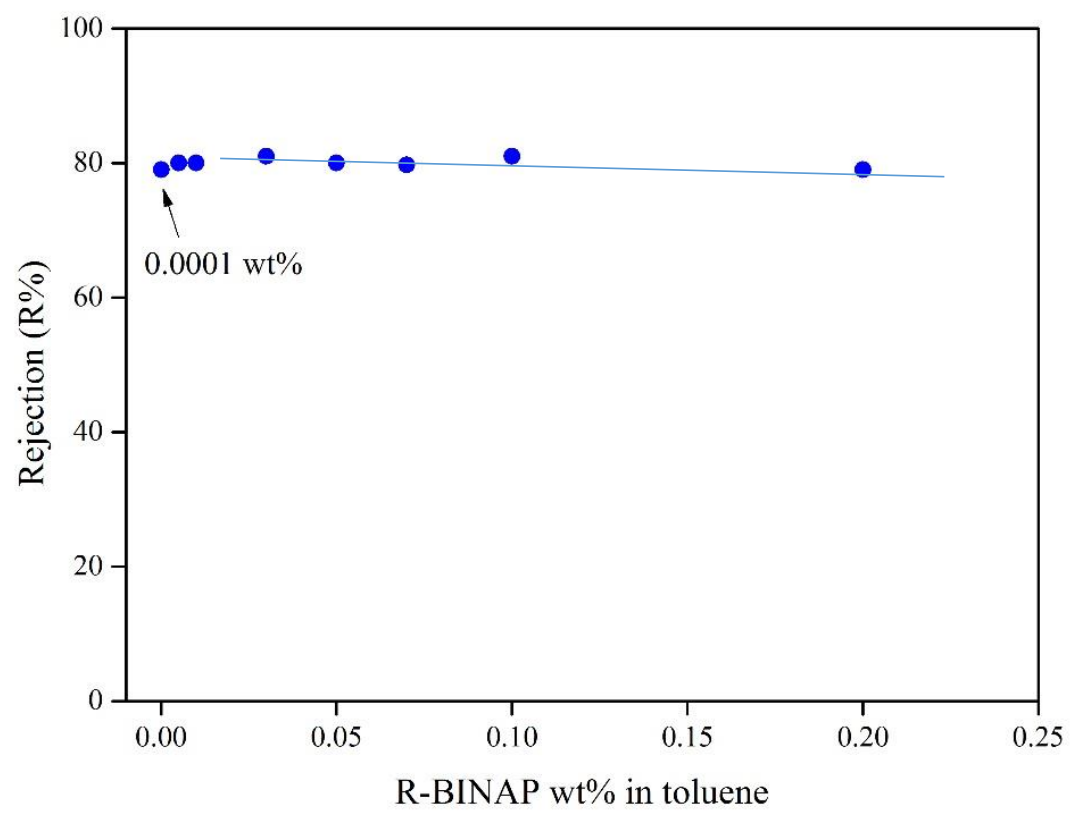

Figure 9: Evaluation of the effect of the concentration of the solute in toluene on its retention by PERVAP4060 (10 bar, $30^{\circ} \mathrm{C}$, concentration range: $0.0001-0.2$ wt\%). Deviation of rejection data: $\pm 2 \%$.

Within the studied range of R-BINAP concentrations, the retention of the solute was almost constant with respect to the measurement accuracy. This indicates that no strong dragging effect could be detected even at high dilution.

\section{e) OSN performance with a model ternary mixture}

A set of experiments was carried out to investigate the retention of diphosphine ligand RBINAP (constant feed concentration: $0.05 \mathrm{wt} \%$ ) from a ternary mixture containing a linear saturated hydrocarbon C16 (feed range: 1 to $10 \mathrm{wt} \%$ ) and toluene. This mixture was intended as a very simple model of a metathesis reaction of linear alkenes. 


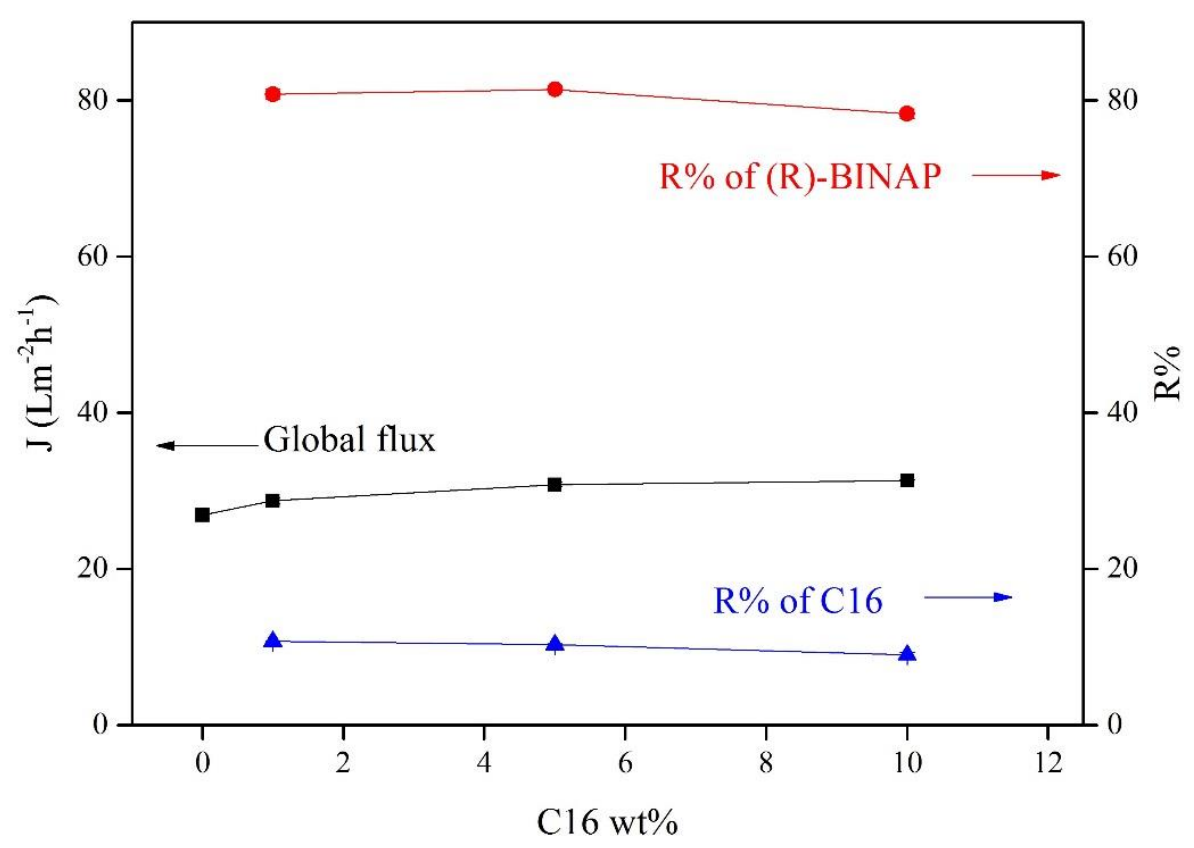

Figure 10: OSN performance of PERVAP4060 for the separation of a model ternary mixture consisting of C16 (1 to $10 \mathrm{wt} \%$ ) and R-BINAP (0.05 wt\%) in toluene (10 bar, $\left.30^{\circ} \mathrm{C}\right)$. Deviation of $\mathrm{J}: \pm 5 \%$.

In Figure 10, the influence of varying the concentration of the linear C16 on the OSN flux and the retentions of R-BINAP and C16 is shown. Interestingly, the retention of R-BINAP remained almost constant at $80 \%$, with only a slight decrease (77\%) occurring at the highest concentration of C16. A similar observation can be made for C16; its retention slightly decreases. The difference between R-BINAP and C16 can be explained by the higher diffusion coefficient which is in relation with the lower molecular weight of the aliphatic solute $(226 \mathrm{~g})$ compared to that of R-BINAP (622 g) and with the correspondingly lower C16 molar volume (Table 2). Another potentially relevant parameter is the lower solubility parameter of C16 compared to that of R-BINAP, which favors its sorption in the active PDMS layer $(\Delta \delta \approx 1)$.

Finally, the results show that the global OSN flux was markedly increased by the presence of the aliphatic solute, up to about $15 \%$ at a $\mathrm{C} 16$ feed concentration of $10 \mathrm{wt} \%$. Aliphatic solute contributes to increasing the swelling of the active layer of the membrane, which favors, in 
turn, the increase of the global-flux of the membrane. Clearly, this flux increase was greater than the simple flux contribution of the linear hydrocarbon.

Moreover, from a process point of view, these results indicate that the OSN method allows easy separation of the linear C16 molecule from R-BINAP in a toluene feed mixture. This is a promising result for its application in olefin metathesis.

\section{CONCLUSION}

The retentions of the tested solutes, phase transfer catalyst $\mathrm{ToABr}$ and diphosphine ligand $\mathrm{R}$ BINAP, were high even at high solute dilutions in toluene, with values of up to $92 \%$ and $80 \%$, respectively. Despite the significant swelling of the PDMS active layer in toluene, there was no indication that the mass transfer obeyed a pore flow mechanism. Conversely, all the results obtained indicate that a solution-diffusion mechanism seems to prevail.

In summary, the main findings related to the use of PERVAP4060 in OSN in this work are:

- The stability of the composite membrane was shown to be excellent under the range of pressures tested (10 to 40 bar), regardless of the degree of solvent-induced swelling of the active layer, i.e., with both ethanol and toluene. A linear increase in the OSN flux was recorded over the tested pressure range at temperatures of up to $50{ }^{\circ} \mathrm{C}$ without any hysteresis effect.

- The retention of dilute solutes (0.05 wt\%), such as ToABr and R-BINAP, which have molecular weights of 546 and $622 \mathrm{~g}$, respectively, were above $80 \%$ for the neutral aromatic solute and above $92 \%$ for the alkyl ammonium salt. This demonstrates that the retention of the solutes was clearly not related to their molecular weights (or molar volume), but was more likely related to the relative affinity of the solute for the membrane active layer and, perhaps most importantly, to the solute mobility.

- In the range of dilutions studied (100 ppm to $0.2 \mathrm{wt} \%$ ) in the toluene feed mixtures, the retention of R-BINAP was constant (80\%). No coupling effect could be detected.

- The OSN flux followed an Arrhenius law with an increase in feed temperature. The energy of activation at 10 bar was higher than at 40 bar, while the retention remained steady. The effect looks very interesting in terms of application. 
- Finally, it was shown that a ternary mixture of the solutes R-BINAP and linear C16 in toluene could easily be fractionated. Most of the C16 alkane was eliminated through the membrane, while the R-BINAP was mainly retained in the feed.

These results highlight the promising OSN potential of PERVAP4060 for the rejection of dilute solutes in metathesis synthesis. All the obtained data were in good agreement with a simple solution-diffusion mechanism through the composite membrane. The high retention level of the R-BINAP solute remained steady even at high dilution. Apparently, the transports of the solute and solvent were not coupled.

\section{Acknowledgments}

This work was achieved in the frame of a collaborative project, ANR-14-CE06-0022, thanks to the financial support of the French National Research Agency and the support of ARKEMA. Professor S. Abbott is also greatly acknowledged for discussion about the Hansen solubility parameters of R-BINAP and ToABr.

\section{REFERENCES}

[1] Gosser L.; Knoth W.H.; Parshall G.W. J. Mol. Catal. 1977, 2, 253-263.

[2] Livingston A.G.; US 2004/0099603 A1.

[3] Marchetti P.; Jimenez Solomon M.F.; Szekely G.; Livingston A.G. Chem. Rev. 2014, 114, 10735-10806.

[4] Patterson D.A.; Lau L.Y.; Roengpithya C.; Gibbins E.J.; Livingston A.G. Desalination 2008, $218,248-256$.

[5] White L.S. J. Membr. Sci. 2006, 286, 26-35.

[6] Noyori R.; Takaya H. Acc. Chem. Res. 1990, 23, 345-350.

[7] Andecochea Saiz C.; Darvishmanesh S.; Buekenhoudt A.; Van der Bruggen B. J. Membr. Sci. 2018, 546,. 120-127.

[8] White L.S. J. Membr. Sci. 2002, 205, 191-202.

[9] Cheng X.Q.;. Zhang Y.L;. Wang Z.X; Guo Z.H.; Bai Y.P.; Shao L. Adv. Polym. Technol. 2014, $33(\mathrm{~S} 1)$. 
[10] Nair D.; Wong H.-T.; Han S.; Vankelecom I.F.J.; White L.S.; Livingston A.G.; Boam A.T; Org. Process Res. Dev. 2009, 13, 863-869.

[11] Székely G.; Valtcheva I.B.; Kim J.F., Livingston A.G. React. Funct. Polym. 2015, 86, 215224.

[12] McKeown N.B; Budd P.M. Macromolecules 2010, 43, 5163-5176.

[13] Alqaheem Y.; Alomair A.; Vinoba M.; Pérez A. Int. J. Polym. Sci. 2017, 1-19.

[14] Ben Soltane H.; Roizard D.; Favre E. J. Membr. Sci. 2013, 435, 110-119.

[15] Wijmans J.G.; Baker R.W. J. Membr. Sci. 1995, 107, 1-21.

[16] Chen A.S.C.; Laneman S.A. 1993/US005202473A.

[17] Mashima K.; Kusano K.; Ohta T.; Noyori R.; Takaya H. J. Chem. Soc. Chem. Commun. 1989, 1208-1210.

[18] De Smet K.; Aert S.; Ceulemans E.; Vankelecom I.F.J.;. Jacobs P.A. Chem. Commun. 2001, 597-598.

[19] Scarpello J.T.; Nair D.; Freitas dos Santos L.M; White L.S.; Livingston A.G. J. Membr. Sci. 2001, 203, 71-85.

[20] Vankelecom I.F.J.; De Smet K.; Gevers L.E.; Livingston A.G.; Nair D.; Aerts S.; Kuypers S.; Jacobs P.A. J. Membr. Sci. 2004, 231, 99-108.

[21] Paul D.R.; Paciotti J.D.; Ebra-Lima O.M. J. Appl. Polym. Sci. 1975, 19, 1837-1845.

[22] Stafie N.; Stamatialis D.F.; Wessling M. Sep. Purif. Technol. 2005, 45, 220-231.

[23] Wong H-T.; See-Toh Y.H.; Ferreira F.C.; Crook R.; Livingston A.G. Chem. Commun. 2006, 2063.

[24] Stamatialis D.F.; Stafie N.; Buadu K.; Hempenius M.; Wessling M. J. Membr. Sci. 2006, $279,424-433$.

[25] Silva P.; Peeva L.G.; Livingston A.G. J. Membr. Sci. 2010, 349, 167-174.

[26] Peeva L.G.; Gibbins E.; Luthra S.S.; White L.S.; Stateva R.P; Livingston A.G. J. Membr. Sci. 2004, 236, 121-136.

[27] Huang L.; Chen J.; Gao T.; Zhang M.; Li Y.; Dai L.; Qu L.; Shi G. Adv. Mater. 2016, 28, 86698674.

[28] Nair D.; Luthra S.S.; Scarpello J.T.; White L.S.; Freitas dos Santos L.M.; Livingston A.G. Desalination. 2002, 147, 301-306. 
[29] Gibbins E.; D’ Antonio M.; Nair D.; White L.S.; Freitas dos Santos L.M.; Vankelecom I.F.J.; Livingston A.G. Desalination, 2002, 147, 307-313.

[30] Luthra S.S.; Yang X.; Freitas Dos Santos L.M.; White L.S.; Livingston A.G. J. Membr. Sci. 2002, 201, 65-75.

[31] Livingston A.G.; Peeva L.; Han S.; Nair D.; Luthra S.S.; White L.S.; Freitas Dos Santos L.M. Ann. N. Y. Acad. Sci. 2003, 984, 123-141.

[32] Lin J.C.-T.; Livingston A.G. Chem. Eng. Sci. 2007, 62, 2728-2736.

[33] Hansen C.M., Hansen Solubility Parameters: A User's Handbook, Second Edition, 2007, CRC Press.

[34] Evans R.; Deng Z.; Rogerson A.K.; McLachlan A.S.; Richards J.J.; Nilsson M.; Morris G.A. Angew. Chem. Int. Ed. 2013, 52, 3199-3202.

[35] Favre E. Eur. Polym. J. 1996, 32, 1183-1188.

[36] Sharma R.R.; Agrawal R.; Chellam S. J. Membr. Sci. 2003, 223, 69-87.

[37] Machado D. R.; Hasson D.; Semiat R. J. Membr. Sci. 1999, 163, 93-102.

[38] Messaâdi A.; Dhouibi N. ; Hamda H. ; Belgacem F. B. M, Y.; Adbelkader H.;

Ouerfelli N.; Hamzaoui H. J.Chem. 2015, Article ID 163262, 1-12

[39] Boucher-Sharma A.P.; Chowdhury G.; Matsuura T. J. Appl. Polym. Sci. 1999, 74, 47-58.

\section{APPENDICES}

Appendice A. Calibration of the GC column for diphosphine ligand R-BINAP detection and an example chromatogram. 


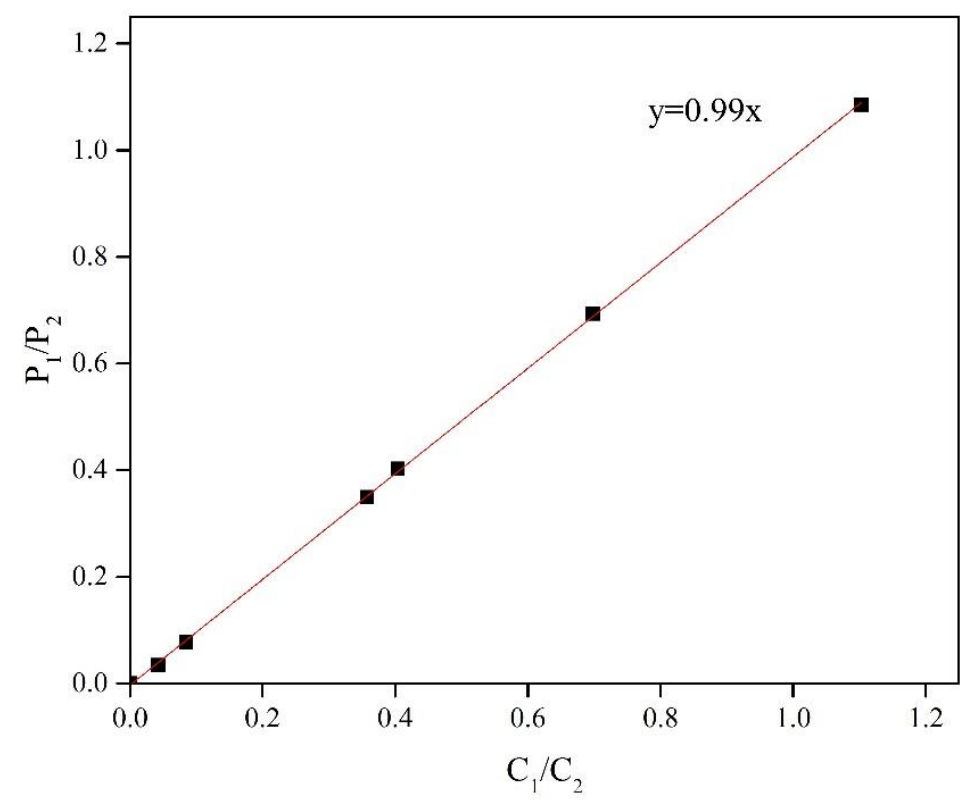

Where $\frac{C 1}{C 2}=\frac{\text { Concentration of } R B I N A P \text { in } w t \%}{\text { Concentration of tetratetracontane in } w t \%}$ and $\frac{P 1}{P 2}=\frac{\text { Peak area of } R B I N A P}{\text { Peak area of tetratetracontane }}$

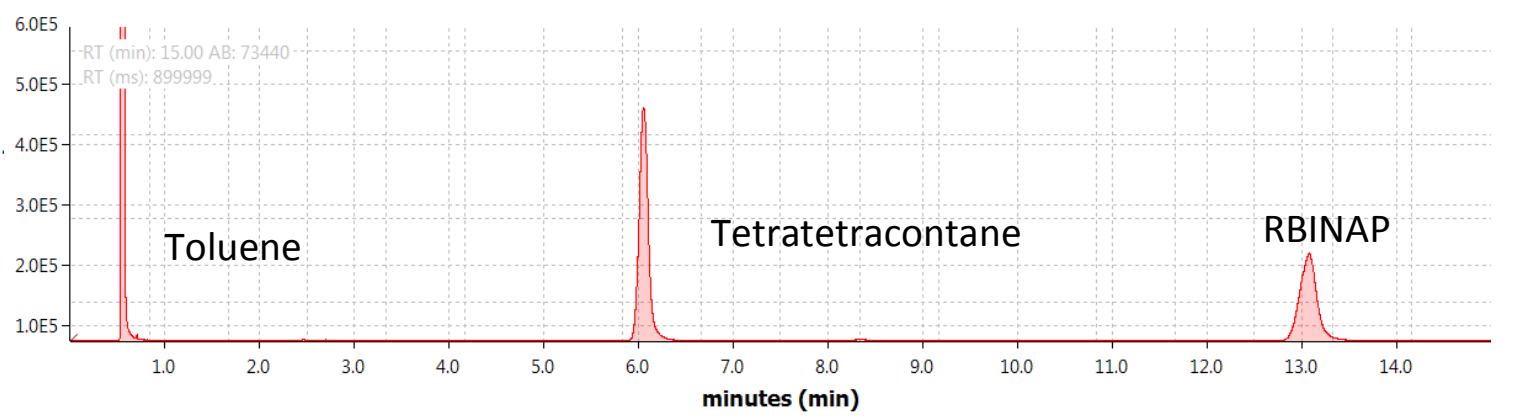


Appendice B. Calibration of the GC column for $\mathrm{ToABr}$ and an example chromatogram.

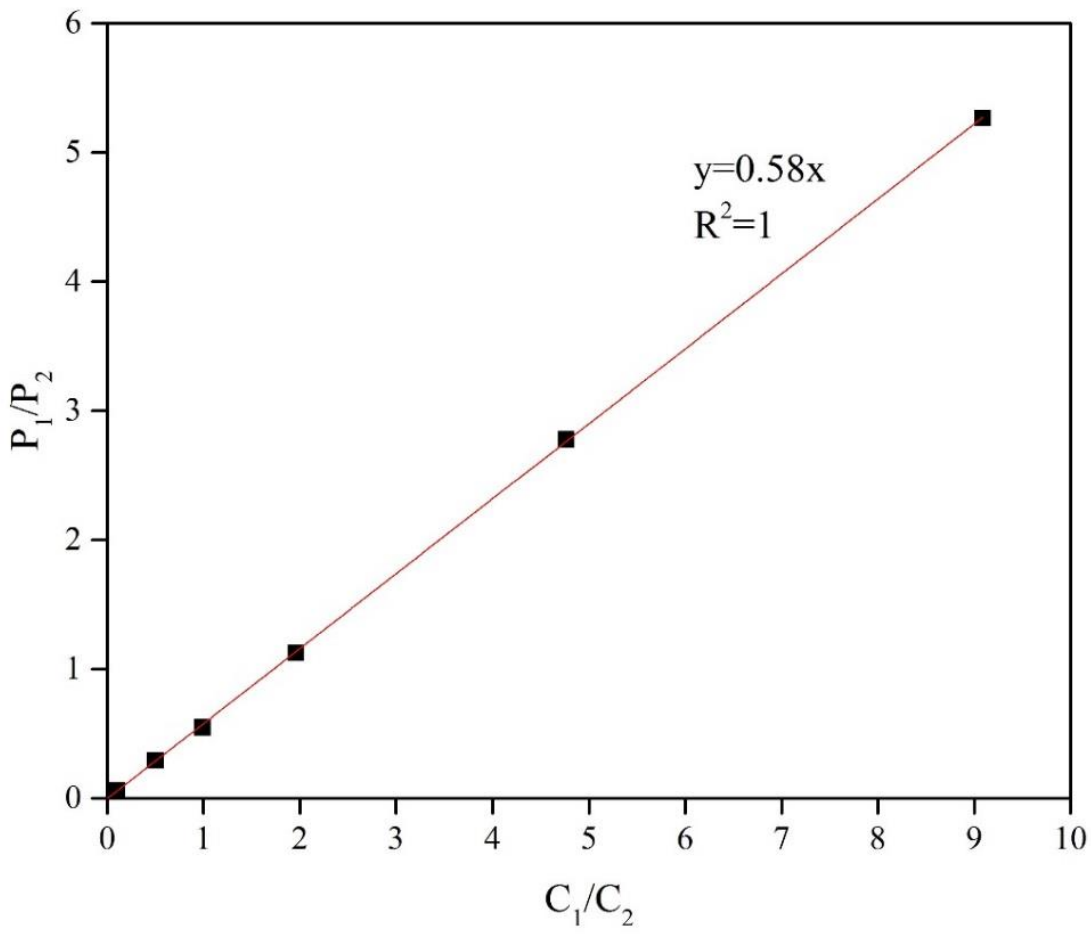

where $\frac{C 1}{C 2}=\frac{\text { Concentration of } T O A B r \text { in } w t \%}{\text { Concentration of } \mathrm{n} \text {-hexadecane } \text { in } w t \%}$ and $\frac{P 1}{P 2}=\frac{\text { Peak area of } \mathrm{TOABr}}{\text { Peak area of } \mathrm{n} \text {-hexadecane }}$

\section{$\mathrm{ToABr}+\mathrm{C} 24$ chromatogram}

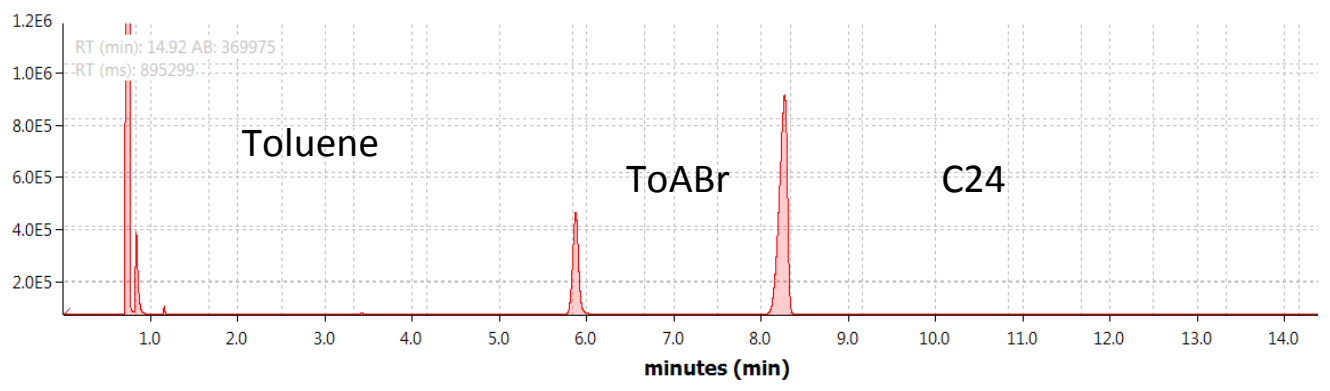


Appendice C. Calibration of the GC column for R-BINAP and C16 ternary mixture.

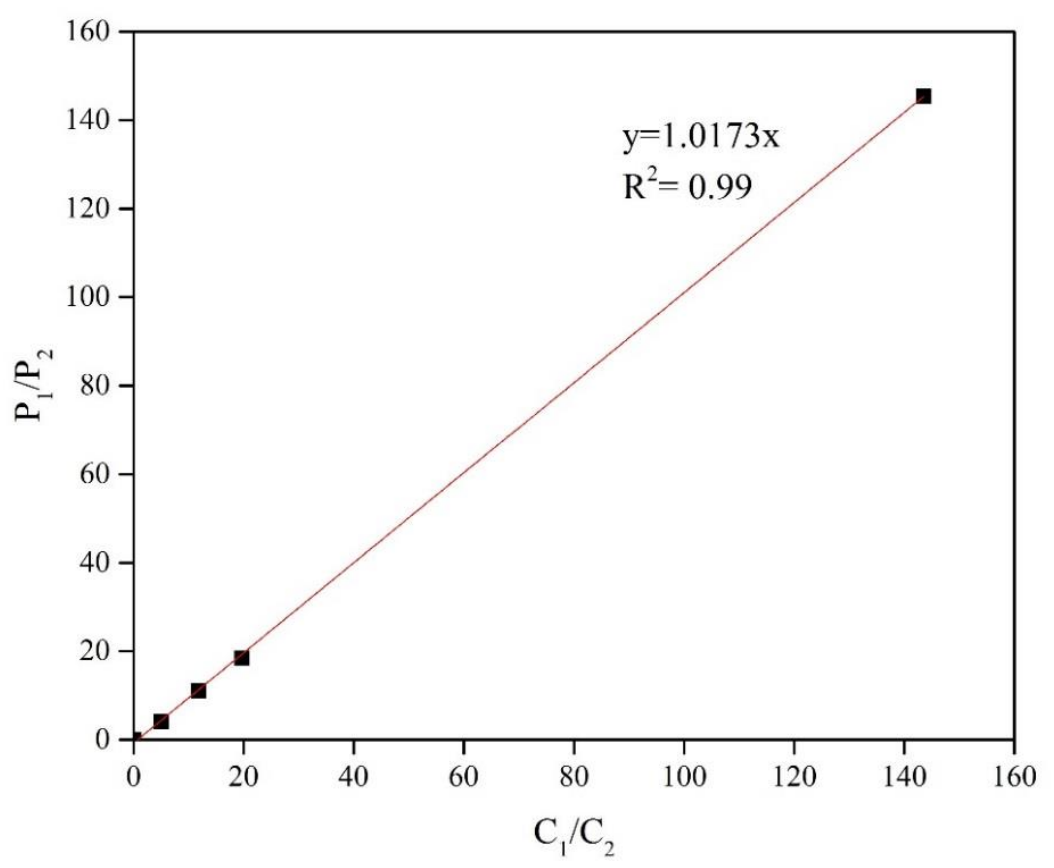

where $\frac{C 1}{C 2}=\frac{\text { Concentration of } R-B I N A P \text { in } w t \%}{\text { Concentration of } \mathrm{n}-\text { hexadecane in } w t \%}$ and $\frac{P 1}{P 2}=\frac{\text { Peak area of } R-B I N A P}{\text { Peak area of } \mathrm{n}-\text { hexadecane }}$ 
Appendices D. Arrhenius plot excluding data at $50{ }^{\circ} \mathrm{C}$.

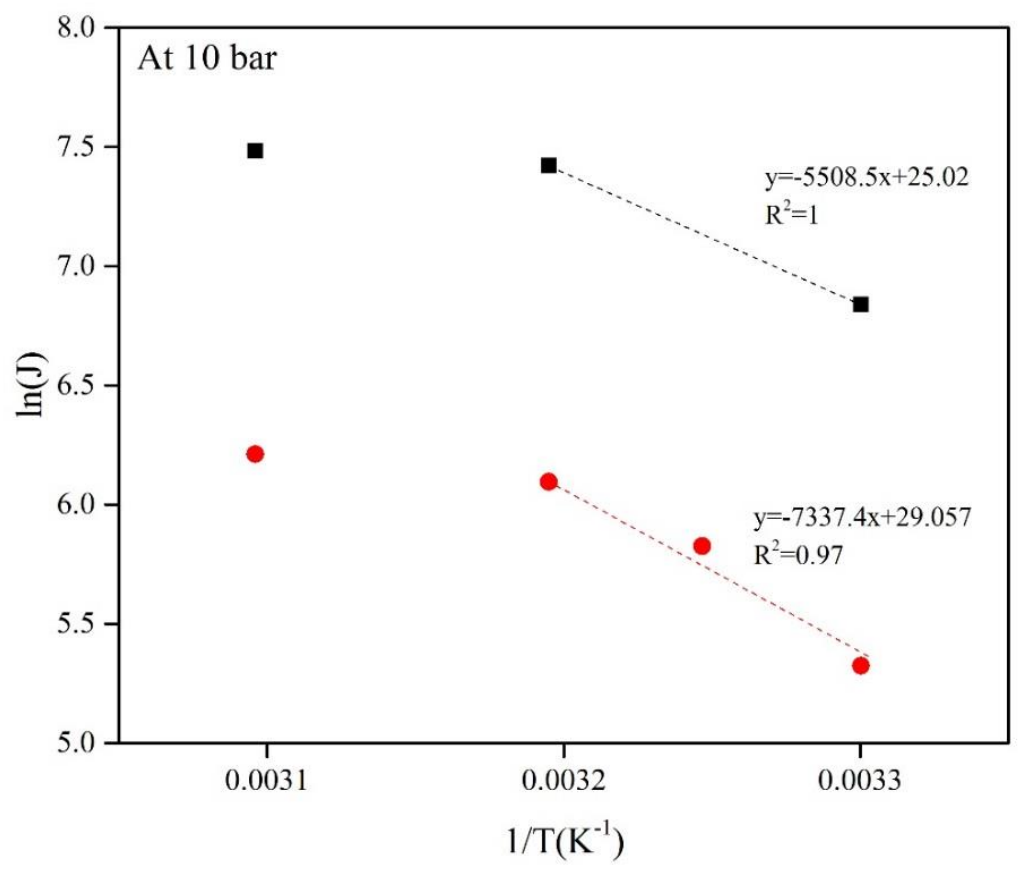




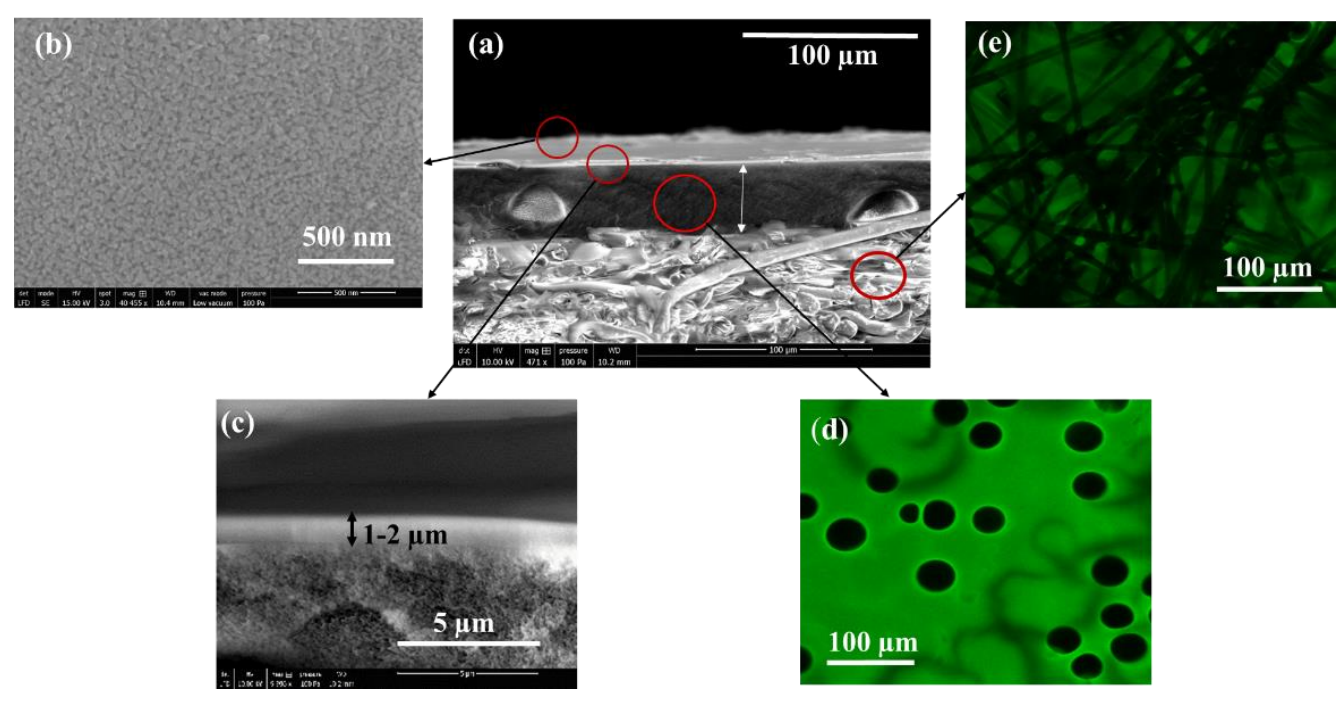

Figure 1: Characterization of the Sulzer PERVAP composite membrane by SEM and confocal microscopic images: (a) Cross-sectional view of the membrane (total thickness 200$220 \mu \mathrm{m}$ ). (b) High resolution image of the PDMS surface. (c) Cross-sectional view of the active layer (PDMS, thickness 1-2 $\mu \mathrm{m}$ ). (d) Top view of the PAN porous sub-layer (25-30 $\mu \mathrm{m})$. (e) PET support layer underneath the PAN sub-layer (170-190 $\mu \mathrm{m})$. 
(a)

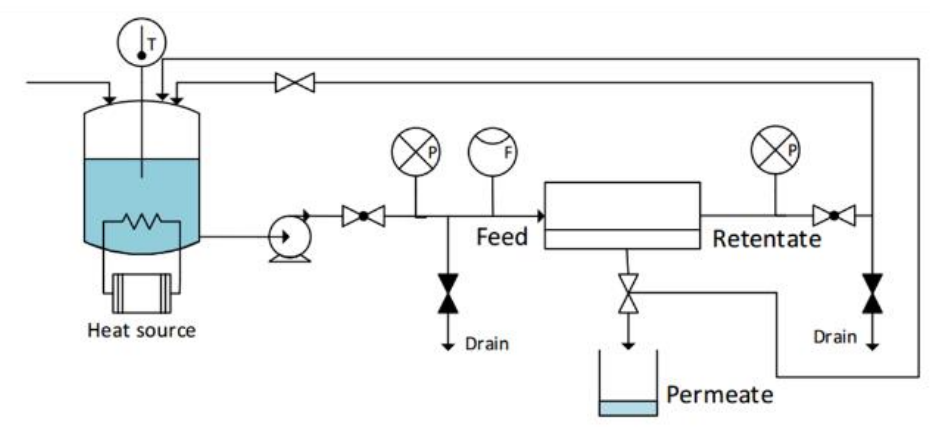

(b)

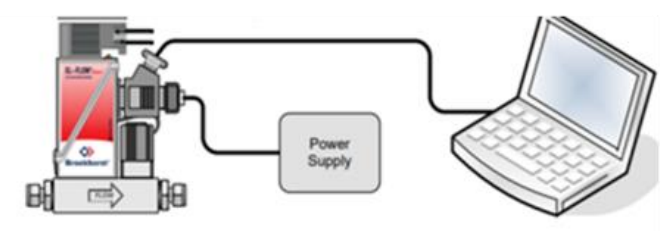

Figure 2: (a) Scheme of the OSN set-up. (b) Digital pressure control system. 
<smiles>c1ccc(-c2ccc3ccccc3c2P(c2ccccc2)c2ccccc2)cc1</smiles>

R-BINAP $(\mathrm{Mw}=624 \mathrm{~g}$ $\left.\mathrm{mol}^{-1}\right)$<smiles>Cl[R](Cl)[PH](c1ccccc1)(c1ccccc1)c1ccc2ccccc2c1-c1c(P(Cl)c2ccccc2)ccc2ccccc12</smiles>

Ru-BINAP $(\mathrm{Mw}=794.6 \mathrm{~g}$ $\left.\mathrm{mol}^{-1}\right)$

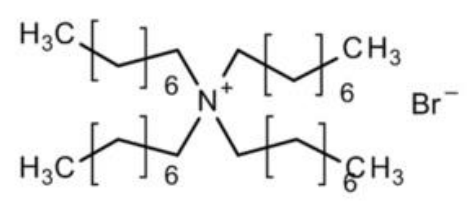

$\operatorname{ToABr}\left(\mathrm{Mw}=546 \mathrm{~g} \mathrm{~mol}^{-1}\right)$

Figure 3: Schematic representations of BINAP, Ru-BINAP and ToABr 


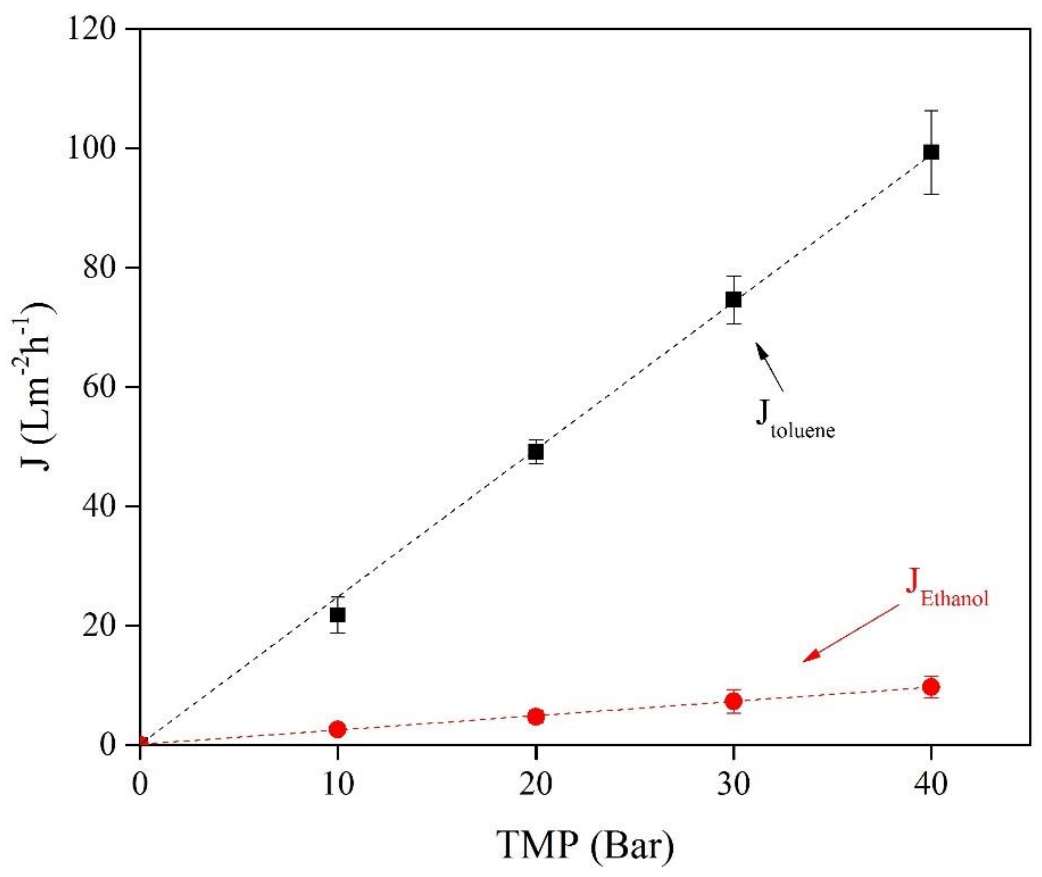

Figure 4: Pure solvent fluxes of EtOH and toluene through PERVAP6040 (deviation $\pm 5 \%$ ). 
A1. Calibration of the GC column for R-BINAP detection and an example chromatogram.

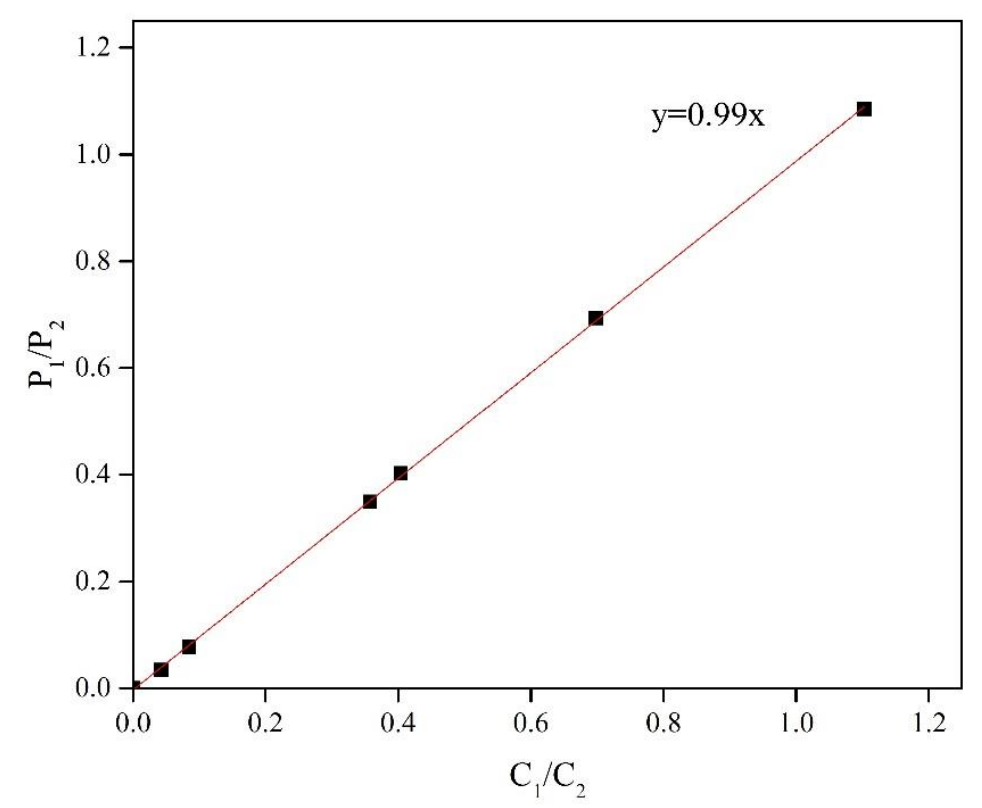

where $\frac{C 1}{C 2}=\frac{\text { Concentration of RBINAP in } w t \%}{\text { Concentration of tetratetracontane in } w t \%}$ and $\frac{P 1}{P 2}=\frac{\text { Peak area of RBINAP }}{\text { Peak area of tetratetracontane }}$

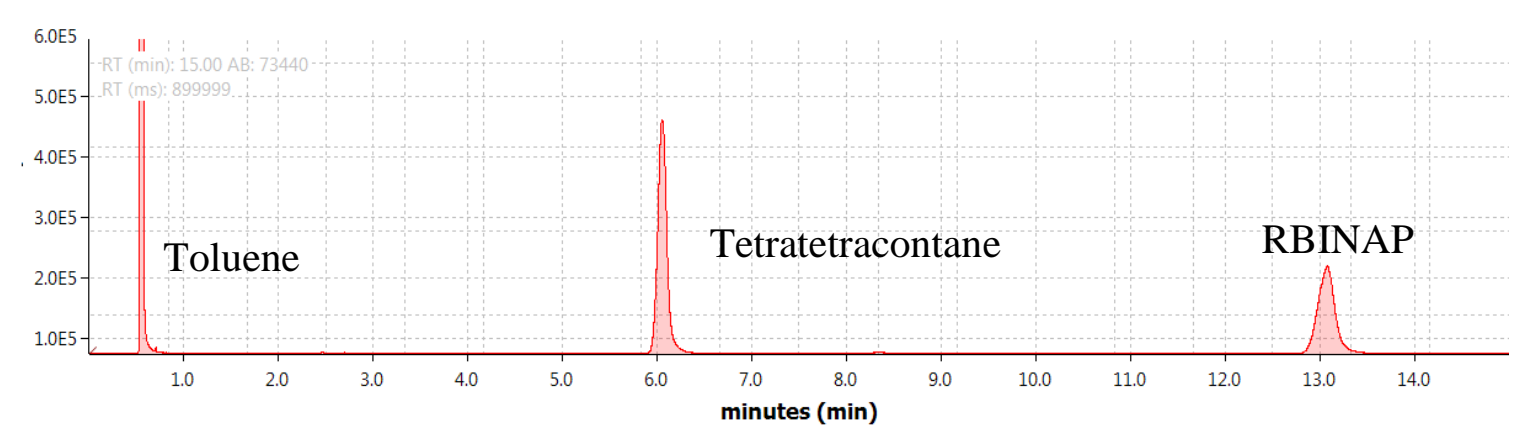


A2. Calibration of the GC column for ToABr and an example chromatogram.

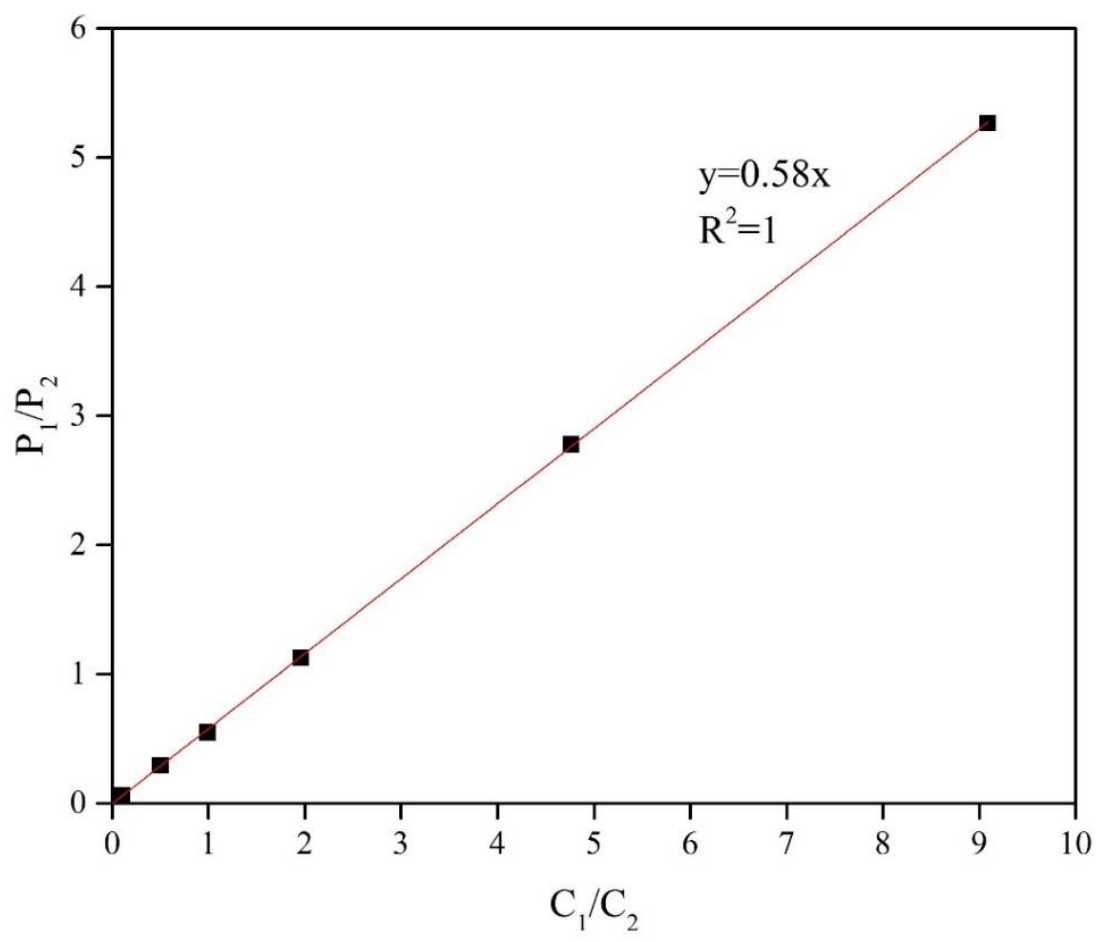

where $\frac{C 1}{C 2}=\frac{\text { Concentration of } T O A B r \text { in } w t \%}{\text { Concentration of } \mathrm{n} \text {-hexadecane } \text { in } w t \%}$ and $\frac{P 1}{P 2}=\frac{\text { Peak area of } T O A B r}{\text { Peak area of } \mathrm{n} \text {-hexadecane }}$

$\mathrm{ToABr}+\mathrm{C} 24$ chromatogram

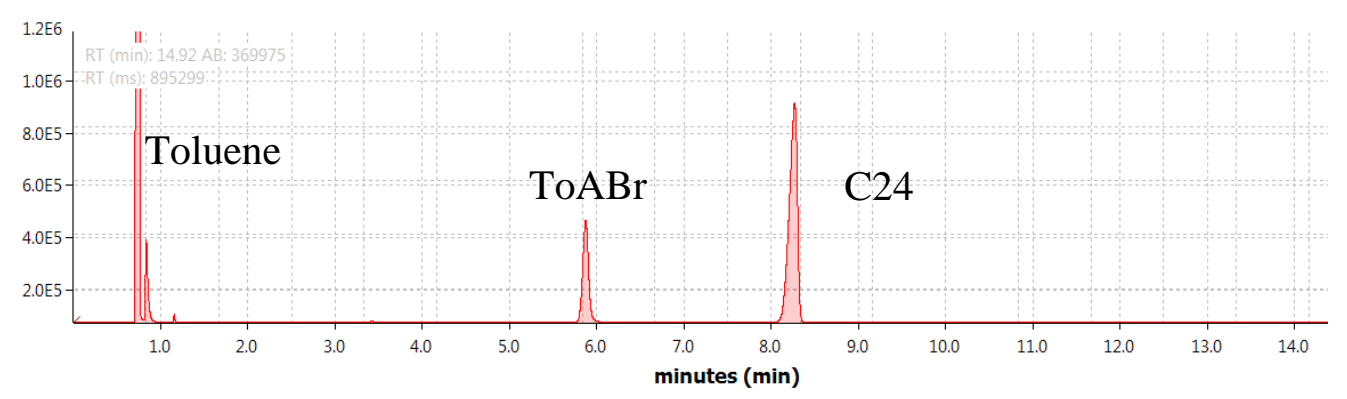


A3. Calibration of the GC column for R-BINAP and C16 ternary mixture.

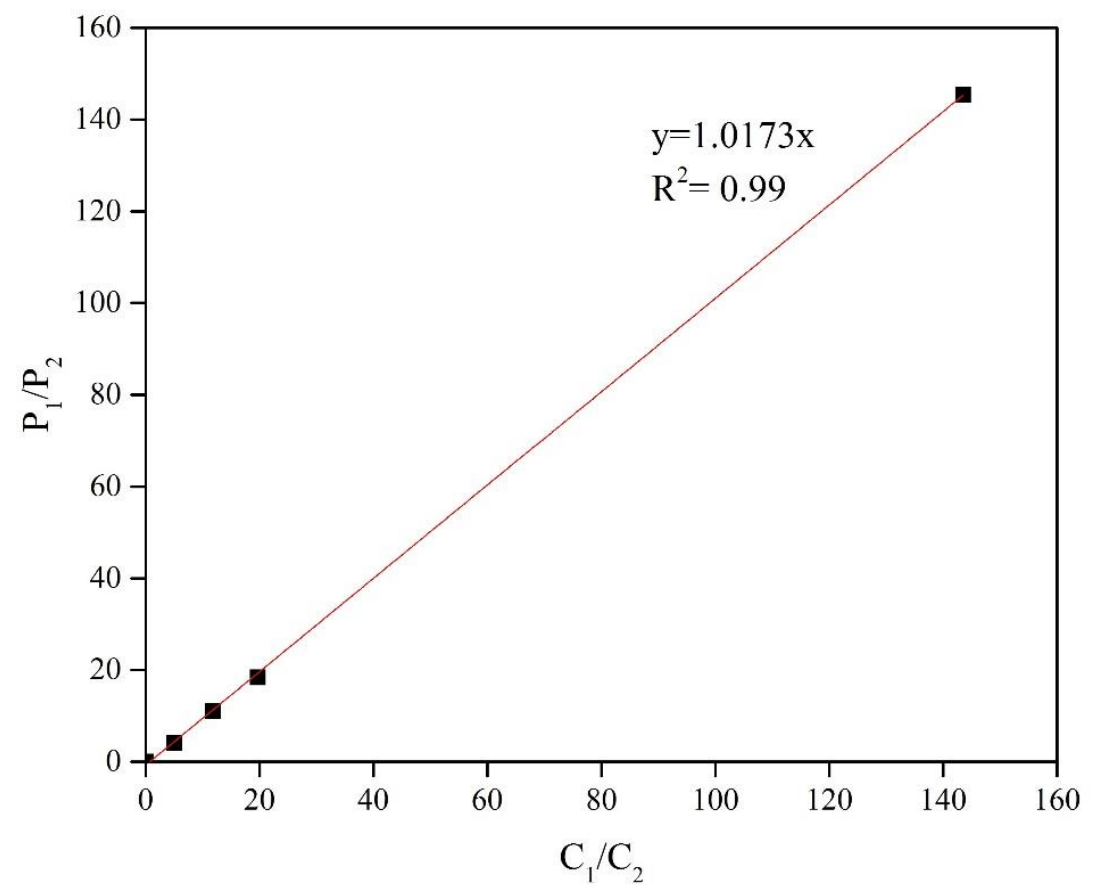

where $\frac{C 1}{C 2}=\frac{\text { Concentration of } R-B I N A P \text { in } w t \%}{\text { Concentration of } \mathrm{n}-\text { hexadecane } \text { in } w t \%}$ and $\frac{P 1}{P 2}=\frac{\text { Peak area of } R-B I N A P}{\text { Peak area of } \mathrm{n}-\text { hexadecane }}$ 
A4. Arrhenius plot excluding data at $50{ }^{\circ} \mathrm{C}$.

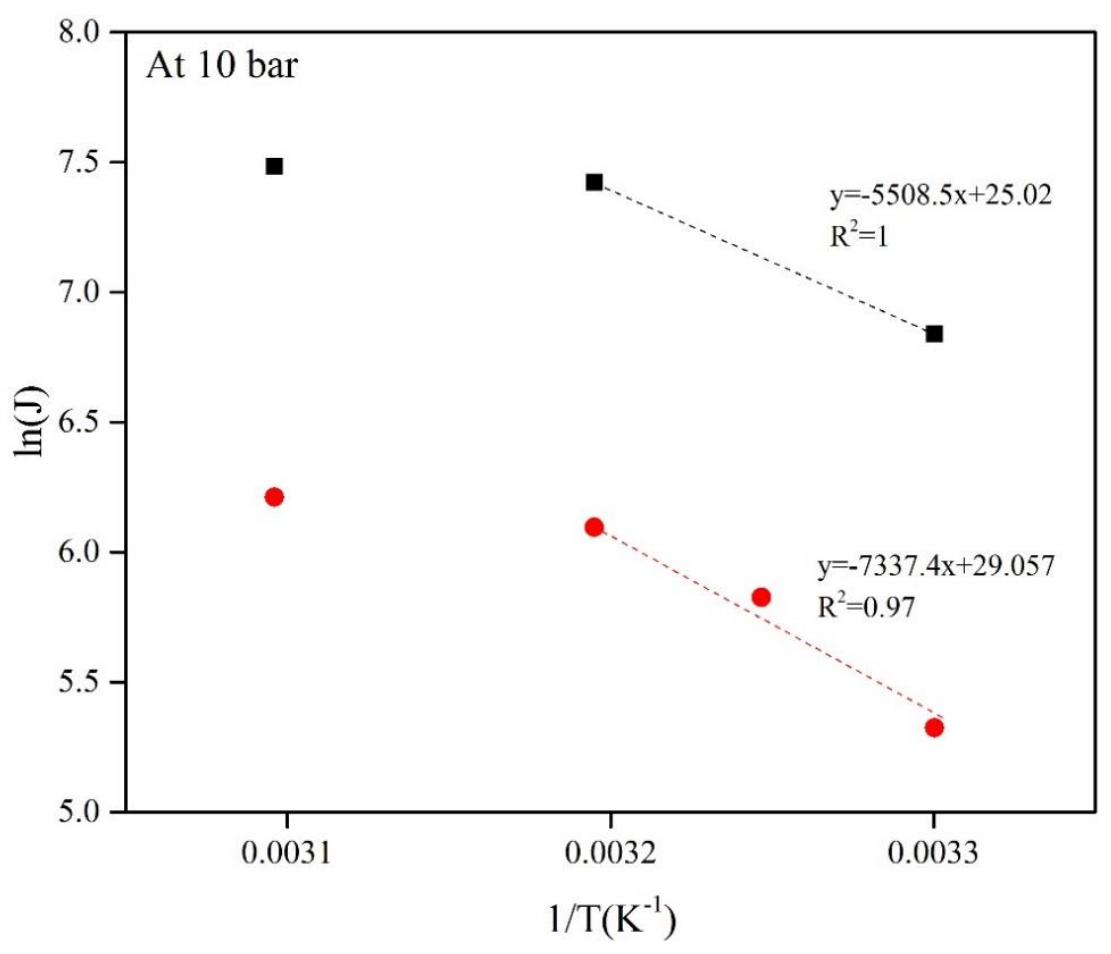




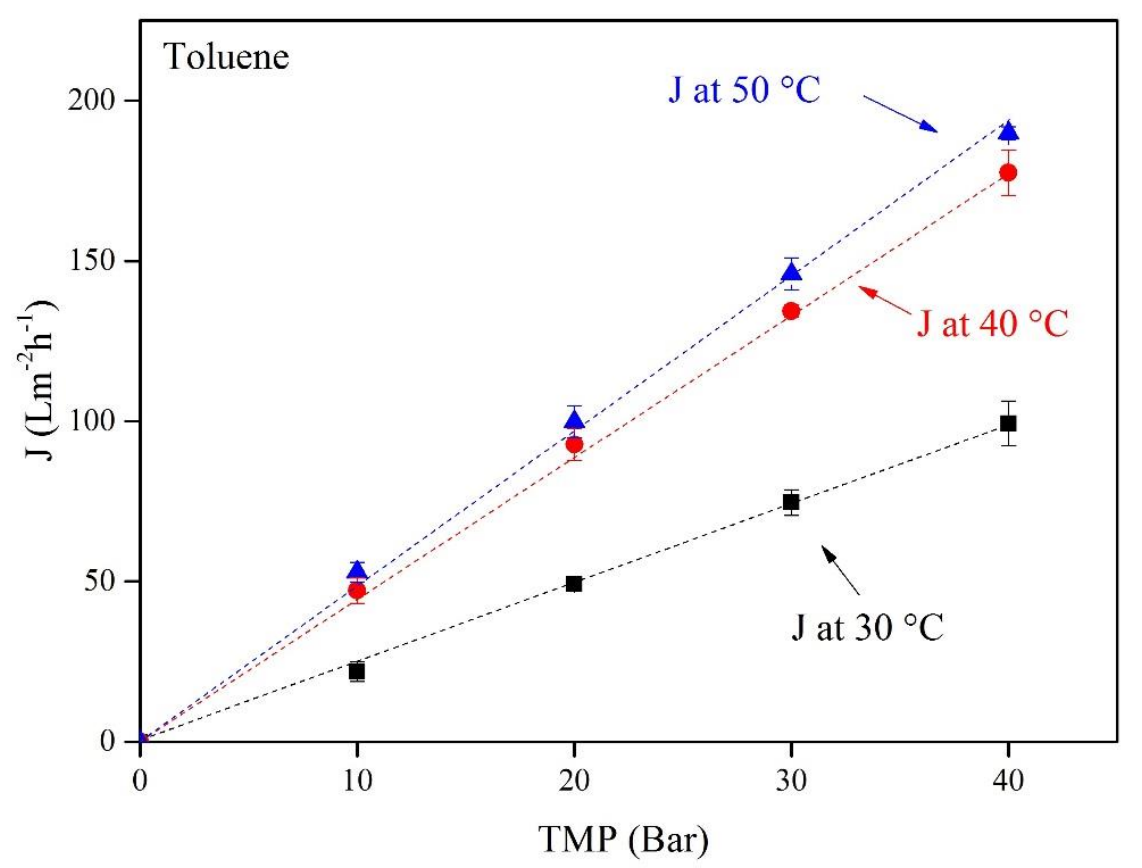

Figure 7: Effect of temperature on the pure toluene fluxes in the OSN system. Deviation \pm $5 \%$. 


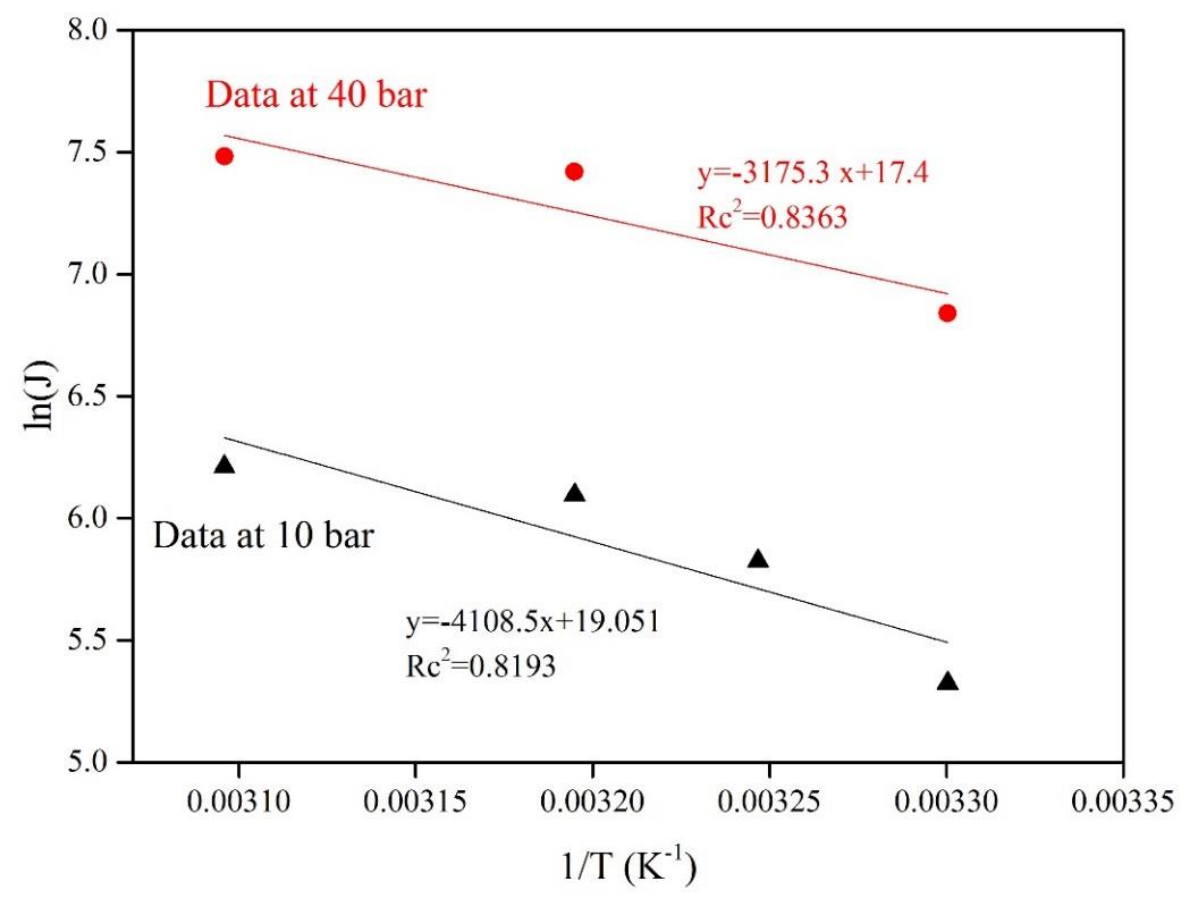

Figure 8: Arrhenius plot of the OSN flux data obtained for PERVAP4060. NB: as the RBINAP concentration was very low $(<0.05 \mathrm{wt} \%)$, the solvent flux has been assimilated to the total OSN flux. Deviation of temperature: $\pm 2{ }^{\circ} \mathrm{C}$. 


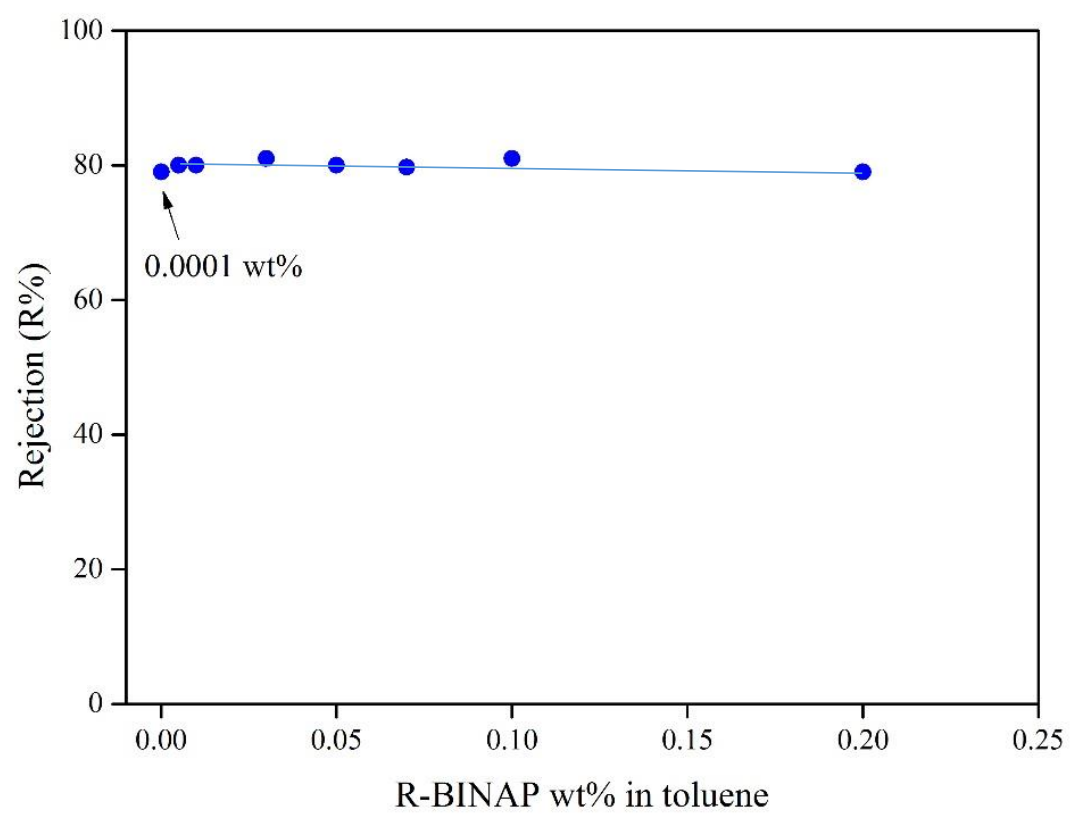

Figure 9: Evaluation of the effect of the concentration of the solute in toluene on its retention by PERVAP4060 (10 bar, $30{ }^{\circ} \mathrm{C}$, concentration range: $0.0001-0.2 \mathrm{wt} \%$ ). Deviation of rejection data: $\pm 2 \%$. 


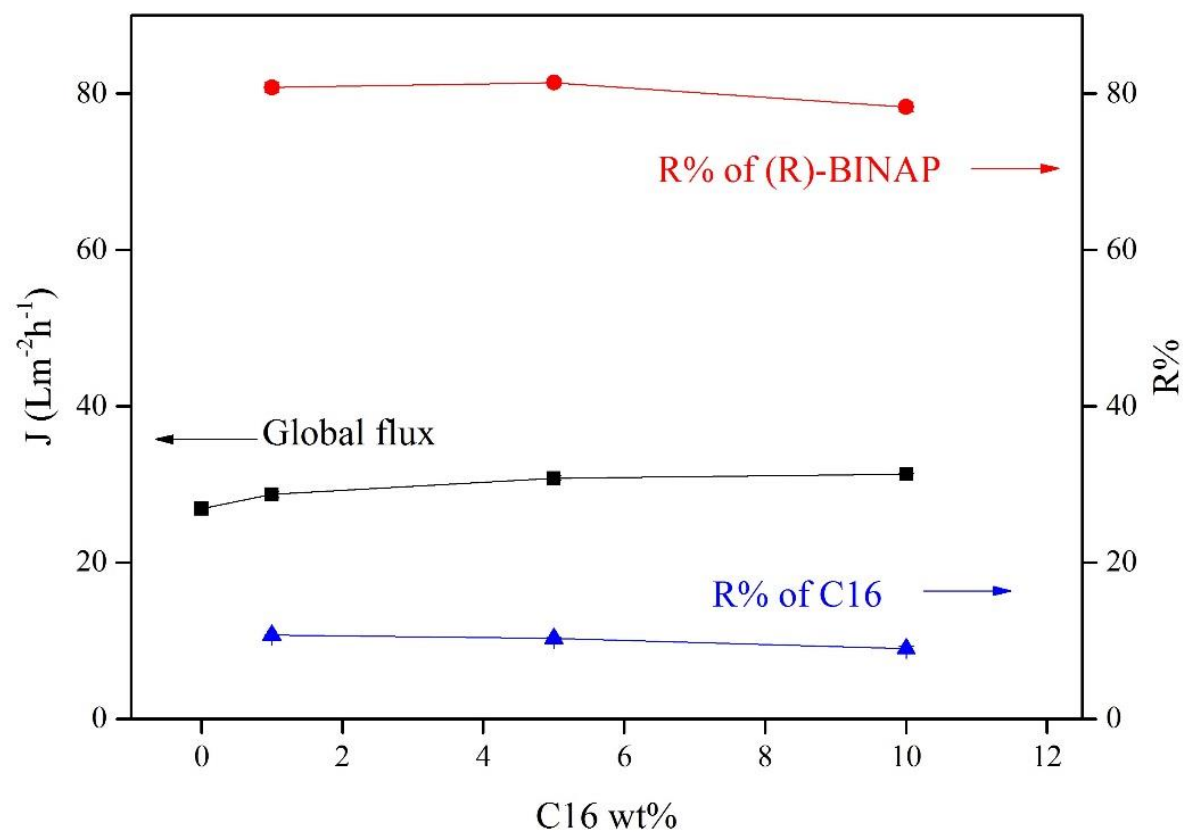

Figure 10: OSN performance of PERVAP4060 for the separation of a model ternary mixture consisting of C16 (1 to $10 \mathrm{wt} \%$ ) and R-BINAP (0.05 wt \%) in toluene (10 bar, $\left.30^{\circ} \mathrm{C}\right)$. ). Deviation of $\mathrm{J}: \pm 5 \%$. 


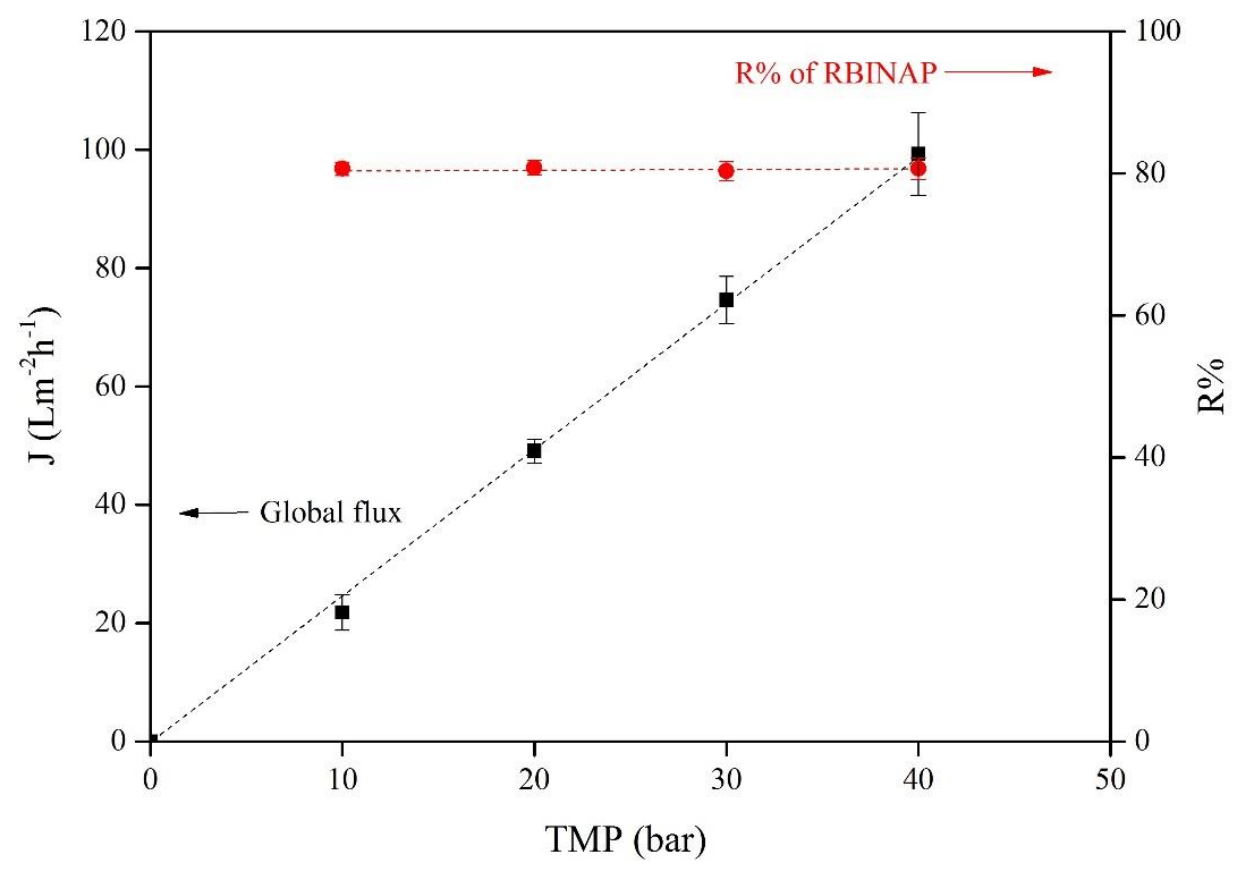

Figure 5: OSN performance of PERVAP4060 for the retention of R-BINAP from a toluene feed solution in the range 1-40 bar. R-BINAP: 0.05 mass $\%$. Note that the J \& R\% values at different TMP correspond to the flux and retention measured after the conditioning procedure. Continuous black line: OSN permeate flux values. Red line: retention values. Deviation $\pm 5 \%$. 


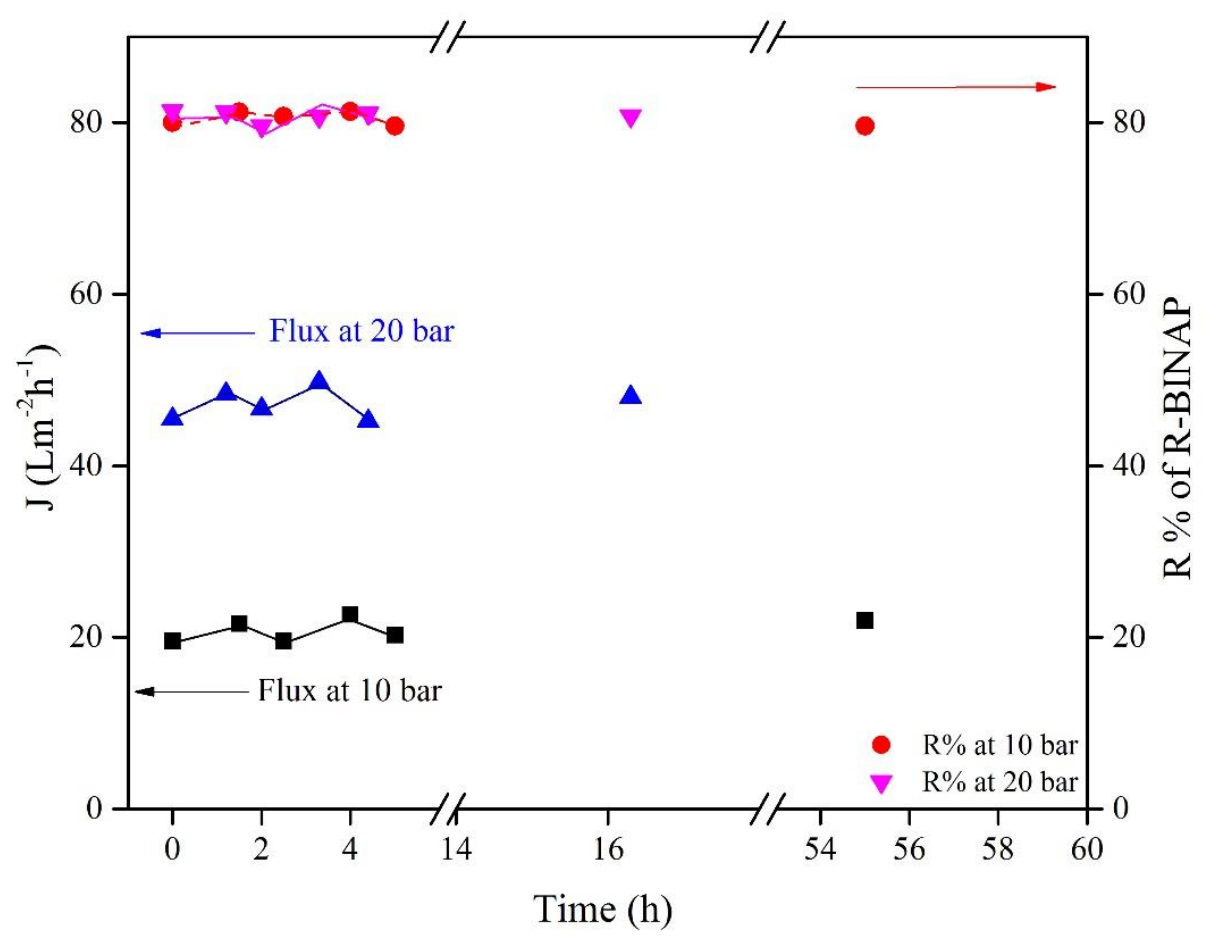

Figure 6: Effect of the applied pressure over time on the OSN flux and R-BINAP retention. Note that the J \& R\% values at zero correspond to the flux and retention measured after the conditioning procedure (feed crossflow $8 \mathrm{Kg} / \mathrm{h} \pm 20 \%, 15-20 \mathrm{~min}$ at each TMP in the range of 0-40 bar). 
Table 1: Literature overview of the retention of BINAP and ToABr catalysts by OSN

\begin{tabular}{|c|c|c|c|c|c|}
\hline $\begin{array}{l}\text { Membrane } \\
\text { (active layer) }\end{array}$ & $\begin{array}{c}\text { Feed } \\
\mathrm{T}\left({ }^{\circ} \mathrm{C}\right), \text { pressure (bar) }\end{array}$ & $\begin{array}{l}\text { Solutes } \\
\text { wt } \%\end{array}$ & $\begin{array}{c}\text { Flux } \\
\mathrm{L} \mathrm{m}^{-2} \mathrm{~h}^{-1}\end{array}$ & $\begin{array}{c}\text { Retention } \\
\%\end{array}$ & Reference \\
\hline MPF60 & $\mathrm{MeOH}, 30^{\circ} \mathrm{C}, 15$ bar & $0.3 \%$ Ru-BINAP & $\sim 2$ & 98 & {$[18]$} \\
\hline MPF50 & $\mathrm{MeOH}, 30^{\circ} \mathrm{C}, 16$ bar & $0.03 \%$ Ru-BINAP & NA & 70 & {$[20]$} \\
\hline MPF 50 & $\mathrm{THF}, 30^{\circ} \mathrm{C}, 25$ bar & 0.04\% Pd-BINAP & 166 & 95.6 & [19] \\
\hline Starmem 122 & $\mathrm{THF}, 30^{\circ} \mathrm{C}, 25$ bar & $0.04 \%$ Pd-BINAP & 93.6 & 100 & [19] \\
\hline Starmem 240 & $\mathrm{EA}, 30^{\circ} \mathrm{C}, 25$ bar & $0.04 \%$ Pd-BINAP & 150.9 & 95.6 & [19] \\
\hline \multirow[t]{2}{*}{ Starmem 122} & $\mathrm{MeOH}+$ ionic liquids $(0.01-10$ & $0.0008 \% \mathrm{Ru}-$ & NA & $95-99.9$ & [23] \\
\hline & wt\%), $35^{\circ} \mathrm{C}, 20$ bar & BINAP & & & \\
\hline Starmem 122 & $\mathrm{MeOH}, 30^{\circ} \mathrm{C}, 30$ bar & $0.005 \%$ Ru-BINAP & 40 & $>97.5$ & {$[10]$} \\
\hline Graph.Oxide & $\mathrm{MeOH}, \mathrm{rt}, 5$ bar & 0.001\% Ru BINAP & 350 & 98 & [27] \\
\hline MPF50 & Toluene, 30 bar & $3 \% \mathrm{ToABr}$ & 19 & 48 & [2] \\
\hline Starmem122 & Toluene, 30 bar & $3 \% \mathrm{ToABr}$ & 14 & $>99$ & {$[28]$} \\
\hline MPF 50 & $\mathrm{MeOH}, 20^{\circ} \mathrm{C}, 30$ bar & $0.3 \%$ Quats & NA & $\sim 95$ & [29] \\
\hline PDMS-PEO & Toluene, $24{ }^{\circ} \mathrm{C}, 10$ bar & $8 \% \mathrm{ToABr}$ & $\sim 16$ & 100 & [24] \\
\hline Starmem 122 & Toluene, $30^{\circ} \mathrm{C}, 30 \mathrm{bar}$ & $20 \% \mathrm{ToABr}$ & $\sim 33$ & 100 & [25] \\
\hline Starmem 122 & Toluene, $30^{\circ} \mathrm{C}, 30 \mathrm{bar}$ & $20 \% \mathrm{ToABr}$ & $\sim 35$ & 98 & [26] \\
\hline Desal 5 & Toluene $20^{\circ} \mathrm{C}$, 30 bar & $3 \% \mathrm{ToABr}$ & 4 & 62 & {$[30]$} \\
\hline Starmem122 & Toluene, $20-23{ }^{\circ} \mathrm{C}, 30$ bar & $3-20 \% \mathrm{ToABr}$ & 70 & $93-97$ & [31] \\
\hline Starmem 122 & $\begin{array}{l}\text { Toluene and } \mathrm{MeOH} \text { mixtures, } \\
\qquad 22^{\circ} \mathrm{C}, 30 \mathrm{bar}\end{array}$ & $\sim 0.2 \% \mathrm{ToABr}$ & 70 & 93 & [32] \\
\hline
\end{tabular}

a) MPF: PDMS active layer; b): STARMEM: polyimide top layer 
Table 2: Some specifications of the used chemicals

\begin{tabular}{ccccccc}
\hline Material & $\begin{array}{c}\text { MW } \\
\text { g/mol }\end{array}$ & $\begin{array}{c}\text { Molecular } \\
\text { diameter } \\
(\mathrm{nm})\end{array}$ & $\begin{array}{c}\text { Molar } \\
\text { volume }^{2} \\
\mathrm{~cm}^{3} \mathrm{~mol}^{-1}\end{array}$ & $\begin{array}{c}\text { Diffusion } \\
\text { coefficient }^{3} \\
\left(\mathrm{~m}^{2} \mathrm{~s}^{-1}\right) \times 10^{+11}\end{array}$ & $\begin{array}{c}\text { Diffusion } \\
\text { coefficient }^{3} \\
\left(\mathrm{~m}^{2} \mathrm{~s}^{-1}\right) \times 10^{+11}\end{array}$ & $\begin{array}{c}\text { Solubility } \\
\text { parameter }^{4} \\
\mathrm{MPa}^{1 / 2}\end{array}$ \\
\hline R-BINAP & 622.7 & NA & 511 & 9.18 & 3.74 & 21.5 \\
ToABr & 546 & NA & 761 & 9.75 & 4.07 & 21.9 \\
C16 & 226 & 0.845 & 294.1 & 14.9 & 7.26 & 15.9 \\
Toluene & 92.1 & 0.56 & 106.8 & 24 & 13.1 & 18.2 \\
EtOH & 46 & 0.52 & 58.5 & 26.4 & 1.7 & 26.5 \\
\hline
\end{tabular}

${ }^{1}$ From literature.

${ }^{2}$ Molar volumes calculated using HSPiP [33] except for that of ToABr [26].

${ }^{3}$ Diffusion co-efficient of toluene and ethanol [14] Other diffusion co-efficient values were calculated using a modified Gierer-Wirtz equation [34].

${ }^{4}$ Solubility parameters were obtained from HsPiP estimation [33]. 
Table 4: Effect of temperature on the OSN flux and diphosphine ligand R-BINAP retention at 10 bar (Feed: $0.05 \%$ R-BINAP, PERVAP4060)

\begin{tabular}{ccc}
\hline Temperature $\left({ }^{\circ} \mathrm{C}\right)$ & $\begin{array}{c}\text { Total flux } \\
\mathrm{J}\left(\mathrm{L} \mathrm{m}^{-2} \mathrm{~h}^{-1}\right) \pm 10 \%\end{array}$ & $\begin{array}{c}\text { R-BINAP retention } \\
0.05 \mathrm{wt} \% \pm 2 \%\end{array}$ \\
\hline 30 & 21 & $80 \pm 2$ \\
35 & 36 & $81 \pm 1$ \\
40 & 47 & $79 \pm 2$ \\
\hline
\end{tabular}


Table 3: Solvent permeance and retention of ToABr by OSN from dilute toluene and EtOH feeds (10 bar, toluene, $\mathrm{EtOH})$

\begin{tabular}{cccccc}
\hline Membrane & Solvent & $\begin{array}{c}\text { ToABr } \\
\text { wt } \%\end{array}$ & $\begin{array}{c}\text { Permeance } \pm 5 \% \\
\mathrm{~L} \mathrm{~m}^{-2} \mathrm{~h}^{-1} \mathrm{bar}^{-1}\end{array}$ & $\begin{array}{c}\text { ToABr } \\
\text { Retention } \\
\% \pm 0.5\end{array}$ & Reference \\
\hline PERVAP4060 & toluene & 1 & $2.2\left(30^{\circ} \mathrm{C}\right)$ & 93.5 & $\underline{\text { This work }}$ \\
PERVAP4060 & toluene & 0.05 & $2.2\left(30^{\circ} \mathrm{C}\right)$ & 93 & This work \\
PERVAP4060 & toluene & 0.1 & $2.2\left(30^{\circ} \mathrm{C}\right)$ & 92.5 & This work \\
PERVAP4060 & toluene & 0.001 & $2.2\left(30^{\circ} \mathrm{C}\right)$ & 93 & $\underline{\text { This work }}$ \\
PERVAP4060 & EtOH & 0.05 & $0.35\left(30^{\circ} \mathrm{C}\right)$ & 95 & $\underline{\text { This work }}$ \\
PERVAP4060 & EtOH & 0.1 & $0.35\left(30^{\circ} \mathrm{C}\right)$ & 95.6 & {$[24]$} \\
PDMS-PEO & toluene & 8 & $1.6\left(24^{\circ} \mathrm{C}\right)$ & 100 & {$[31]$} \\
MPF 60 & toluene & 3 & 0.2 to 1.9 & 48 to 86 & {$[18]$} \\
MPF 60 & MeOH & 0.3 & $0.13\left(30^{\circ} \mathrm{C}\right)$ & 98 & 98 \\
\hline
\end{tabular}

